\title{
Isolation and Assessment of the Molecular and Electronic Structures of Azo-Anion-Radical Complexes of Chromium and Molybdenum. Experimental and Theoretical Characterization of Complete Electron-Transfer Series
}

\author{
Sucheta Joy, ${ }^{\dagger}$ Tobias Krämer, ${ }^{\ddagger}$ Nanda D. Paul, ${ }^{\dagger}$ Priyabrata Banerjee, ${ }^{+, \S}$ John E. McGrady, ${ }^{*, \neq}$ and \\ Sreebrata Goswami ${ }^{*},+$ \\ ${ }^{\dagger}$ Department of Inorganic Chemistry, Indian Association for the Cultivation of Science, Kolkata 700 032, India \\ ${ }^{\ddagger}$ Inorganic Chemistry Laboratory, Department of Chemistry, University of Oxford, South Parks Road, Oxford OX1 3QR, U.K. \\ Supporting Information
}

ABSTRACT: The reaction of 3 equiv of the ligand 2-[(2-chlorophenyl)azo $]$ pyridine $\left(\mathrm{L}^{\mathrm{a}}\right)$ or 2-[(4-chlorophenyl)azo]pyridine $\left(\mathrm{L}^{\mathrm{b}}\right)$ with 1 equiv of $\mathrm{Cr}(\mathrm{CO})_{6}$ or $\mathrm{Mo}(\mathrm{CO})_{6}$ in boiling $n$-octane afforded $\left[\mathrm{Cr}\left(\mathrm{L}^{\mathrm{a} / \mathrm{b}}\right)_{3}\right]^{0}$ (1a and $\mathbf{1 b})$ and $\left[\mathrm{Mo}\left(\mathrm{L}^{\mathrm{a} / \mathrm{b}}\right)_{3}\right]^{0}(\mathbf{2 a}$ and $\mathbf{2 b})$. The chemical oxidation reaction of these neutral complexes with $\mathrm{I}_{2}$ in $\mathrm{CH}_{2} \mathrm{Cl}_{2}$ provided access to air-stable one-electron-oxidized species as their triiodide $\left(\mathrm{I}_{3}{ }^{-}\right)$salts. The electronic structures of chromium and molybdenum centers coordinated by the three redox noninnocent ligands $\mathrm{L}^{\mathrm{a} / \mathrm{b}}$ along with their redox partners have been elucidated by using a host of physical methods: X-ray crystallography, magnetic susceptibility measurements, nuclear magnetic resonance, cyclic voltammetry, absorption spectroscopy, electron paramagnetic resonance spectroscopy, and density functional theory. The four representative complexes, 1a, $[1 \mathrm{a}] \mathrm{I}_{3}, \mathbf{2 a}$,

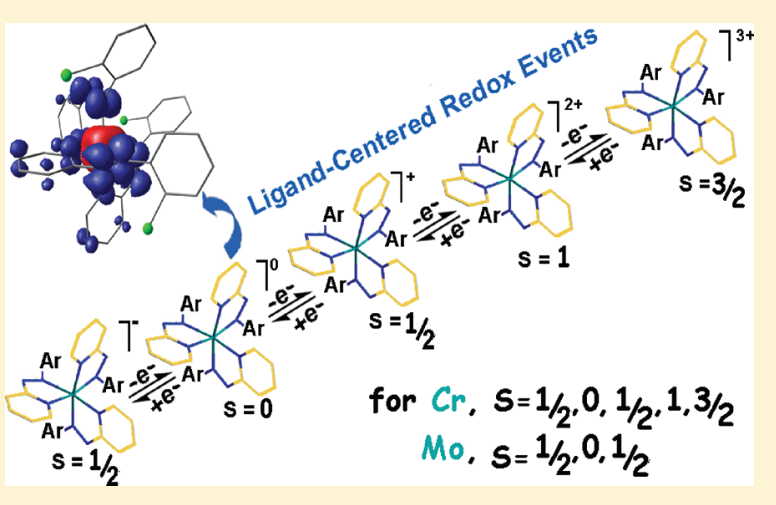
and $[2 \mathrm{a}] \mathrm{I}_{3}$, have been characterized by X-ray crystallography. The results indicate a predominant azo-anion-radical description of the ligands in the neutral chromium(III) species, $\left[\mathrm{Cr}^{\mathrm{III}}\left(\mathrm{L}^{\bullet-}\right)_{3}\right]$, affording a singlet ground state through strong metalligand antiferromagnetic coupling. All of the electrochemical processes are ligand-based; i.e., the half-filled $\left(t_{2 g}\right)^{3}$ set of the Cr ${ }^{I I I} d^{3}$ ion remains unchanged throughout. The description of the molybdenum analogue is less clear-cut because mixing between metaland ligand-based orbitals is more significant. On the basis of variations in net spin densities and orbital compositions, we argue that the oxidation events are again primarily ligand-based, although the electron density at the molybdenum center is clearly more variable than that at the chromium center in the corresponding series $[\mathbf{1 a}]^{+}, \mathbf{1 a}$, and $[\mathbf{1 a}]^{-}$.

\section{INTRODUCTION}

Transition-metal complexes with redox noninnocent ligands have generated much interest in recent years because of an increased curiosity about the potential role of ligand/metal-centered redox events in biological processes, organic transformations, smallmolecule activation, and so forth. ${ }^{1-3}$ The close energetic proximity of the metal $\mathrm{d}$ and frontier ligand orbitals creates a complicated situation with several close-lying electronic states. ${ }^{4-6}$ Establishing the exact metal-ligand valence-state balance in each redox state therefore requires a careful evaluation of structural, spectroscopic, and theoretical data. The chelating $o$-quinone/ $o$-semiquinone/catecholate-type redox system has been most thoroughly studied, and statistically derived guidelines to aid in structure-oxidation state correlations have been presented. ${ }^{4,7}$

In recent years, we and others ${ }^{8,9}$ have explored the chemistry of coordination complexes of azoaromatic ligands, potential members of the redox noninnocent family of ligands. Although the azo-anion-radical oxidation state has been known in solution ${ }^{10}$ for many years, its isolation in the pure crystalline state was first reported only in $1998 .^{11}$ Chemical or electrochemical transfer of one or two electrons to the acceptor azo function of these azoaromatics results in either a radical monoanion or a hydrazido dianion, respectively. ${ }^{8-12}$ The electrochemical series in a representative example, 2-(arylazo)pyridine (pap), is depicted in Scheme 1. ${ }^{8 \mathrm{a}, 11 \mathrm{~b}}$ It is now well established that azoaromatic ligands also have the fundamental ability to stabilize low-oxidation-state ${ }^{13}$ metal centers via $\mathrm{d} \pi$ (metal) $-\mathrm{p} \pi$ (azo) back-donation. Conversely, the reduced ligands prefer high-valent metal centers., ${ }^{8,14}$

Two decades ago, Ackermann et al. reported ${ }^{15}$ the synthesis of neutral trischelates $\left[\mathrm{M}(\mathrm{L})_{3}\right]$ of $\mathrm{Cr}, \mathrm{Mo}$, and $\mathrm{W}$, where the ligand $\mathrm{L}$ is 2 -(phenylazo)pyridine. These compounds were primarily characterized by their spectroscopic properties. Subsequently, in 2002, the X-ray structure of a related compound, [Mo(4-methyl2 -(phenylazo)pyridine $\left.)_{3}\right]$, was reported. ${ }^{16}$ The most notable feature of the structure is the unusual elongation of the $\mathrm{N}=\mathrm{N}$ bond

Received: April 7, 2011

Published: September 20, 2011 


\section{Scheme 1}

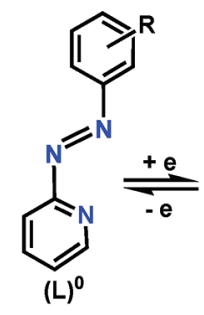

$\mathrm{d}(\mathrm{N}-\mathrm{N}) \quad \mathbf{1 . 2 5 - 1 . 3 0 \AA}$

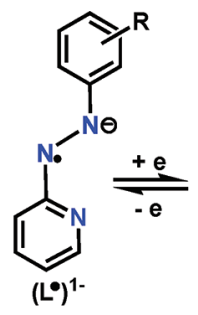

ca. $1.35 \AA$

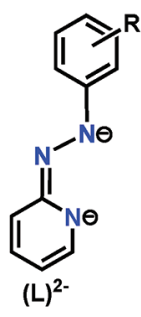

$1.40-1.45 \AA$ lengths relative to those in the free ligand, ${ }^{17}$ an observation that would be consistent with the radical monoanionic character in the coordinated ligands. These authors, however, described these systems as zerovalent complexes of group VI metal ions, and the bond length elongation in the reference complexes was ascribed to extensive Mo $\rightarrow$ L $\pi$ back-donation. ${ }^{13}$ The electrochemical oxidation processes were therefore interpreted as metal-based, whereas the reductions were ligand-based. The ligand radical formulation of the neutral species would necessarily imply the opposite, that the oxidation process is ligand-based. This example neatly illustrates the ambiguity in describing the electronic structure of this class of systems: the crystallographic experiment is sensitive only to the total electron density in the $\mathrm{N}=\mathrm{N} \pi^{*}$ orbital and thus cannot easily distinguish a ligand-radical situation (where a single electron is transferred to the $\pi^{*}$ orbital) from strong backbonding (where a pair of electrons is shared between the metal $\mathrm{d}$ orbital and the $\pi^{*}$ unit of the ligand).

In recent years, the use of low-valent metal precursors has allowed us to isolate several stable azo-anion-radical complexes. ${ }^{8 \mathrm{a}, \mathrm{b}}$ We have also shown that internal electron transfer in these complexes is common, resulting in the isolation of azo-anion metal complexes in which the actual oxidation state of the metal ions is higher than that in the starting complexes. With this background in mind, we set out to revisit the systems $\mathrm{M}(\mathrm{L})_{3}$ $(\mathrm{M}=\mathrm{Cr}, \mathrm{Mo})$ with the aim of establishing a definitive assignment of their electronic structures. In addition to the neutral compounds, we have also isolated the chemically oxidized monocationic complexes as pure crystalline salts, and several other members of the redox series have been generated and characterized in solution. Their structural and spectroscopic properties, along with a detailed analysis of their electronic structures using density functional theory (DFT), provide a platform for understanding the detailed nature of the redox-induced electron redistributions in these compounds.

Structural parameters, spectroscopic data, and DFT calculations all point to a predominant azo-anion-radical description ${ }^{8}$ of the ligands in the neutral chromium(III) species $\left[\mathrm{Cr}^{\mathrm{III}}\left(\mathrm{L}^{\bullet-}\right)_{3}\right]$. Moreover, all of the electrochemical processes are ligand-based; i.e., the half-filled $\left(\mathrm{t}_{2 \mathrm{~g}}\right)^{3}$ set of the $\mathrm{Cr}^{\mathrm{III}} \mathrm{d}^{3}$ ion remains unchanged throughout. In this regard, it should be mentioned that examples of neutral complexes of chromium with three radical ligands are scarce in the literature. ${ }^{18,19}$ In related cases, the electronic structures were presented in the closed-shell form such as in $\left.\left[\mathrm{Cr}^{\mathrm{VI}} \text { (dithiolene }\right)_{3}\right]^{7 \mathrm{a}, \mathrm{b}}$ and $\left[\mathrm{Cr}^{\mathrm{O}}(\mathrm{bpy})_{3}\right] .{ }^{18 \mathrm{c}}$ This may primarily be due to a lack of availability of their single-crystal X-ray structures. Stronger mixing of the metal and ligand orbitals in the molybdenum complexes makes analysis of their electronic structure more complicated, although it is clear that the redox events remain primarily ligand-based.

\section{Chart 1}

\begin{tabular}{|c|c|c|c|c|c|}
\hline \multicolumn{2}{|c|}{ Ligand } & \multicolumn{3}{|c|}{ Metal Complex } & \\
\hline $\mathbf{R}$ & $\mathbf{L}$ & M $=$ Chromi & & M = Molybder & \\
\hline \multirow{2}{*}{$O-\mathrm{Cl}$} & \multirow{2}{*}{$\mathbf{L}^{\mathbf{a}}$} & {$\left[\mathbf{C r}\left(\mathrm{L}^{\mathrm{a}^{\bullet-}}\right)_{3}\right]$} & 1a & {$\left[\mathrm{Mo}\left(\mathrm{L}^{\mathrm{a}^{\bullet-}}\right)_{3}\right]$} & $2 a$ \\
\hline & & {$\left[\mathrm{Cr}\left(\mathrm{L}^{\mathrm{a}^{\circ-}}\right)_{2}\left(\mathrm{~L}^{\mathrm{a}}\right)\right] \mathrm{I}_{3}$} & {$[\mathbf{1} \mathbf{a}] \mathbf{I}_{3}$} & {$\left[\mathrm{Mo}\left(\mathrm{L}^{\mathrm{a}^{\circ-}}\right)_{2}\left(\mathrm{~L}^{\mathrm{a}}\right)\right] \mathrm{I}_{3}$} & {$[2 \mathbf{a}] \mathbf{I}_{3}$} \\
\hline \multirow{2}{*}{$p^{-C l}$} & \multirow{2}{*}{$\mathbf{L}^{\mathbf{b}}$} & {$\left[\mathrm{Cr}\left(\mathrm{L}^{\mathrm{b \bullet -}}\right)_{3}\right]$} & 1b & {$\left[\mathrm{Mo}\left(\mathrm{L}^{\mathrm{b \bullet}}\right)_{3}\right]$} & $2 \mathbf{b}$ \\
\hline & & {$\left[\operatorname{Cr}\left(L^{b^{\bullet-}}\right)_{2}\left(L^{b}\right)\right] I_{3}$} & {$[1 \mathbf{b}] \mathbf{I}_{3}$} & {$\left[\mathrm{Mo}\left(\mathrm{L}^{\mathrm{b}}\right)_{2}\left(\mathrm{~L}^{\mathrm{b}}\right)\right] \mathrm{I}_{3}$} & {$[2 \mathrm{~b}] \mathrm{I}_{3}$} \\
\hline
\end{tabular}

\section{RESULTS}

Syntheses and Characterization. Two isomeric chloro-substituted ligands, $\mathrm{L}^{\mathrm{a}}$ (ortho) and $\mathrm{L}^{\mathrm{b}}$ (para), have been used in this work. The ligands and isolated complexes are collected in Chart 1. The choice of chloro-substituted ligands was prompted by our previous observations that they generally produce high-quality crystals for X-ray structure determination. It may be relevant to add here that the isolated species are a valuable tool in evaluating the extent of electron transfer to the ligand (vide infra). ${ }^{8 a, 13}$ The reactions of $\mathrm{M}(\mathrm{CO})_{6}(\mathrm{M}=\mathrm{Cr}, \mathrm{Mo} ; 1.0 \mathrm{mmol})$ with the ligands $\mathrm{L}^{\mathrm{a}}$ or $\mathrm{L}^{\mathrm{b}}(3.0 \mathrm{mmol})$ in boiling $n$-octane produced green $\mathrm{M}\left(\mathrm{L}^{\mathrm{a} / \mathrm{b}}\right)_{3}$ complexes (1a, $\mathbf{1 b}, \mathbf{2} \mathbf{a}$, and $\mathbf{2} \mathbf{b}$ ) in almost quantitative yields (>90\%). Complexes $\mathbf{1 a}, \mathbf{1} \mathbf{b}, \mathbf{2} \mathbf{a}$, and $\mathbf{2} \mathbf{b}$ gave satisfactory elemental analyses (see the Experimental Section). Electrospray ionization mass spectrometry (ESI-MS) spectra of the complexes corroborate their formulation as $\left[\mathrm{M}\left(\mathrm{L}^{\mathrm{a} / \mathrm{b}}\right)_{3}\right]$ : for example, complexes 1a and 2a showed intense peaks due to the molecular ions at $m / z 705 \mathrm{amu}\left([\mathbf{1 a}]^{+}\right)$and $m / z 750 \mathrm{amu}\left([\mathbf{2} \mathbf{a}]^{+}\right)$, respectively. The isotope patterns of the complexes correspond very well to the simulations. Representative spectra of $\mathbf{1 a}$ and $2 \mathbf{a}$ along with the simulations are submitted as Figures S1 and S2 in the Supporting Information. One-electron oxidation of $\mathbf{1 a}$ and $\mathbf{2 a}$ with iodine in a dichloromethane solvent produced the cationic complexes $[\mathbf{1 a}]_{3}$ and $[\mathbf{2 a}] \mathrm{I}_{3}$, respectively, in nearly quantitative yields.

X-ray Crystallography. Single-crystal X-ray structure determination of the chromium and molybdenum complexes $1 \mathbf{1 a}$ and 2a revealed coordination geometries similar to that of the previously reported ${ }^{16} \mathrm{Mo}\left(4-\mathrm{CH}_{3} \text {-2-(phenylazo)pyridine }\right)_{3}$; they are considered together for comparison. Oak Ridge thermal-ellipsoid plot (ORTEP) and atom numbering schemes of the above complexes are shown in Figures 1 and 2, and selected bond parameters are collected in Table 1 . In both complexes, the central metal ions are coordinated by the three azoaromatic ligands $\mathrm{L}^{\mathrm{a}}$. $\mathrm{X}$-ray crystallographic analysis of the complexes reveals considerably distorted octahedral structures. The averages of the chelate bite angles ${ }^{8}$ are significantly smaller than the ideal octahedral angle of $90^{\circ} ; \mathrm{N}($ pyridyl $)-\mathrm{Cr}-\mathrm{N}($ azo $)=76.41^{\circ} ; \mathrm{N}($ pyridyl $)-\mathrm{Mo}-\mathrm{N}-$ $(\mathrm{azo})=72.95^{\circ}$. Moreover, the average trigonal twist angle $\left(\Theta_{\mathrm{av}}\right)$ is $39.4^{\circ}$ for $1 \mathrm{a}$ and $34.5^{\circ}$ for $\mathbf{2 a}$ (Table 1 ). In both structures, each azo nitrogen atom lies trans to a pyridyl nitrogen atom. The most notable feature of these two structures is the unusual elongation of the $\mathrm{N}-\mathrm{N}$ bonds of the azo chromospheres compared to that of the free ligand: in complex 1a, the three $\mathrm{N}-\mathrm{N}$ bond lengths are $1.345(3), 1.345(3)$, and 1.341(3) $\AA$ (Table 1). The vibrational frequency $v(\mathrm{~N}=\mathrm{N})$ in 1 a is lower $\left(1180 \mathrm{~cm}^{-1}\right)$ compared to that of the uncoordinated ligand salt $\left[\mathrm{HL}^{\mathrm{a}}\right] \mathrm{ClO}_{4}[v(\mathrm{~N}=\mathrm{N})=$ $\left.1437 \mathrm{~cm}^{-1}\right] .{ }^{17}$ The elongation of the azo unit is even more pronounced in 2a: two of the azo bond lengths are identical at $1.356(2) \AA$, while the third one is a bit longer at 1.361(2) $\AA$. 


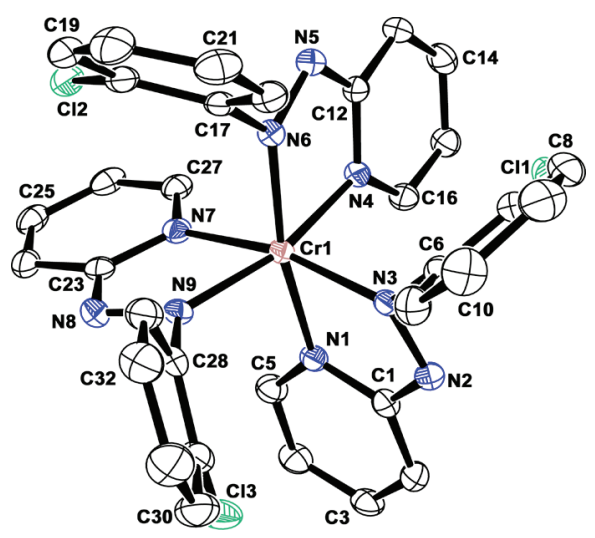

Figure 1. ORTEP representation and atom numbering scheme of complex 1a $\cdot \mathrm{CH}_{2} \mathrm{Cl}_{2}$. Hydrogen atoms and solvent molecules are omitted for clarity.

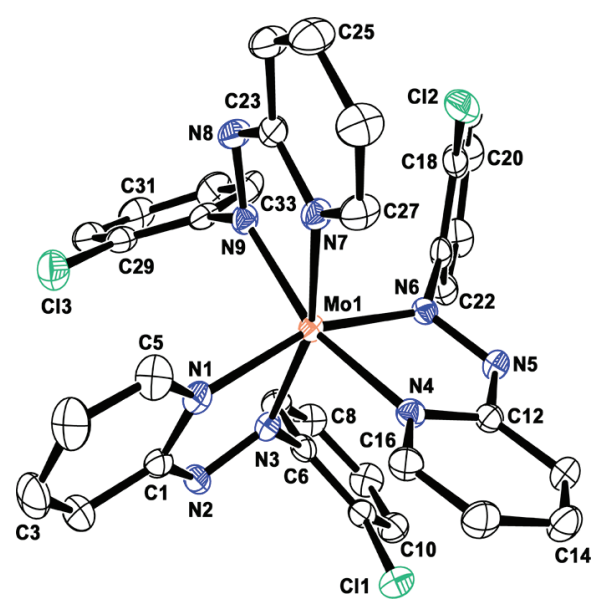

Figure 2. ORTEP representation and atom numbering scheme of complex $2 \mathrm{a} \cdot 2 \mathrm{CH}_{2} \mathrm{Cl}_{2}$. Hydrogen atoms and solvent molecules are omitted for clarity.

The one-electron-oxidized complexes $[\mathbf{1} \mathbf{a}] \mathrm{I}_{3}$ and $[\mathbf{2} \mathbf{a}] \mathrm{I}_{3}$ were isolated in highly crystalline forms. The ORTEP representations with atom numbering schemes of the complexes $[\mathbf{1} \mathbf{a}] \mathrm{I}_{3}$ and $[\mathbf{2 a}] \mathrm{I}_{3}$ are displayed in Figures 3 and 4, respectively. The coordination geometries of the oxidized complexes are similar to those of the neutral analogues $1 \mathrm{a}$ and $\mathbf{2 a}$ with average trigonal twist angles $\left(\Theta_{\text {av }}\right) 39.3^{\circ}$ and $35.4^{\circ}$ for $[\mathbf{1 a}] \mathrm{I}_{3}$ and $[\mathbf{2} \mathbf{a}] \mathrm{I}_{3}$, respectively (Table 1 ). The most striking difference between the neutral $1 \mathrm{a}$ and cationic $[1 \mathrm{a}] \mathrm{I}_{3}$ species is the notable contraction of the average $\mathrm{N}-\mathrm{N}$ bond lengths and also the emergence of a small degree of asymmetry (Table $1 ; d(\mathrm{~N}-\mathrm{N})$ lengths in $[\mathbf{1 a}] \mathrm{I}_{3}$ are 1.314(5), 1.316(5), and 1.334(5) $\AA$ ). A similar oxidation-induced contraction of $d(\mathrm{~N}-\mathrm{N})$ is observed in $[2 \mathrm{a}] \mathrm{I}_{3}$ but with a larger degree of asymmetry with $d(\mathrm{~N}-\mathrm{N})=1.339(5), 1.341(5)$, and 1.383(6) $\AA$. The asymmetry observed in the $\mathrm{N}-\mathrm{N}$ bond lengths is clearly reflected in their IR stretching frequencies: $2 \mathrm{a}, 1140$ and $1165 \mathrm{~cm}^{-1}$; $[\mathbf{1 a}] \mathrm{I}_{3}, 1180$ and $1215 \mathrm{~cm}^{-1}$; [2a $] \mathrm{I}_{3}, 1140$ and $1195 \mathrm{~cm}^{-1}$. $\mathrm{aa}$

Magnetic Susceptibility. Variable-temperature magnetic susceptibility measurement on a polycrystalline sample of $1 \mathrm{a}(2-290 \mathrm{~K})$ indicates that the effective magnetic moment of $1 \mathrm{a}$ is constant at $\sim 0.24 \mu_{\mathrm{B}}$ over the range $35-240 \mathrm{~K}$ but drops to a limiting lowtemperature value of $0.22 \mu_{\mathrm{B}}$ at $2 \mathrm{~K}$ (Figure S3 in the Supporting
Information). Above $240 \mathrm{~K}$, an increase in the effective magnetic moment is consistent with the population of an excited state. Complex 1a, therefore, has an $S=0$ ground state (Figure S3 in the Supporting Information) but with substantial temperatureindependent paramagnetism. Wieghardt and co-workers have noted very similar features in a closely related $\left[\mathrm{Cr}^{\mathrm{III}}(\mathrm{SQ})_{3}\right]$ complex (where $\mathrm{SQ}=o$-semiquinone) ${ }^{18 \mathrm{a}}$ The singlet ground state can be interpreted in terms of strong antiferromagnetic coupling between the metal and ligand radicals, a situation that is typical of this class of complexes. ${ }^{18,19}$ The Heisenberg spin Hamiltonian for 1a can be represented as ${ }^{20} \hat{H}=-2 J_{1}\left(\hat{S}_{\mathrm{Cr}} \cdot \hat{S}_{\mathrm{Lig} 1}+\right.$ $\left.\hat{S}_{\mathrm{Cr}} \cdot \hat{S}_{\mathrm{Lig} 2}+\hat{S}_{\mathrm{Cr}} \cdot \hat{S}_{\mathrm{Lig} 3}\right)+2 J_{2}\left(\hat{S}_{\mathrm{Lig} 1} \cdot \hat{S}_{\mathrm{Lig} 2}+\hat{S}_{\mathrm{Lig} 2} \cdot \hat{S}_{\mathrm{Lig} 3}+\hat{S}_{\mathrm{Lig} 3} \cdot\right.$ $\left.\hat{S}_{\mathrm{Lig} 1}\right)$. The metal-ligand and ligand-ligand couplings are, of course, intimately linked, and supposing that the ligand-ligand coupling is negligible relative to that of the chromium-ligand coupling, the Hamiltonian is simplified to $-2 \hat{S}_{\mathrm{Cr}}\left(\hat{S}_{\mathrm{Lig} 1}+\hat{S}_{\mathrm{Lig} 2}+\right.$ $\left.\hat{S}_{\mathrm{Lig3}}\right)$. Furthermore, the three ligand spin vectors can be combined into one total ligand spin vector $\hat{S}_{\mathrm{Lig}}\left(\right.$ where $S_{\mathrm{Lig}}=3 / 2$ ) because they are effectively ferromagnetically coupled as a result of their strong antiferromagnetic interactions with the chromium center. Using the simplified Hamiltonian ${ }^{21} \hat{H}=-2 J \hat{S}_{\mathrm{Cr}} \cdot \hat{S}_{\mathrm{Lig}}$, the experimental data can be fit with $\chi_{\mathrm{TIP}}=0.596 \times 10^{-4} \mathrm{~cm}^{3} \mathrm{~mol}^{-1}$, $\theta=-2 \mathrm{~K}, g=2.00$ (fixed), and $J=-700 \mathrm{~cm}^{-1}$ (see Figure S3 in the Supporting Information for simulations using various values for $J)$ and a small amount of paramagnetic impurity $(S=1 / 2$, $1.9 \%)$. The residual paramagnetism in compound $1 \mathrm{a}$ resulted in a broadening of the ${ }^{1} \mathrm{H}$ NMR spectrum. In comparison, the molybdenum complex 2a displays sharp ${ }^{1} \mathrm{H}$ NMR signals in the normal range for diamagnetic compounds. The ${ }^{1} \mathrm{H}$ NMR spectra of $1 \mathbf{a}$ and 2a are submitted as Supporting Information (Figures S4 and S5).

Variable-temperature magnetic susceptibility measurements were also carried out on polycrystalline samples of the one-electronoxidized analogues $[\mathbf{1} \mathbf{a}] \mathrm{I}_{3}$ and $[\mathbf{2} \mathbf{a}] \mathrm{I}_{3}$ in the temperature range $2-290 \mathrm{~K}: \mu_{\text {eff }}$ is plotted against $T$ for $[\mathbf{1 a}] \mathrm{I}_{3}$ and $[\mathbf{2 a}]_{3}$ (Figure 5). At $\sim 10 \mathrm{~K},[1 \mathrm{a}] \mathrm{I}_{3}$ displays an effective moment approaching the spin-only value for an $S=1 / 2$ system $\left(\mu_{\text {eff }}=\right.$ $\left.1.73 \mu_{\mathrm{B}}\right)$. However, $\mu_{\mathrm{eff}}$ rises to a plateau of $1.93 \mu_{\mathrm{B}}$ above $50 \mathrm{~K}$ (Figure 5). Analogous behavior has been reported for a manganese(IV) diradical system, also with $S=1 / 2$, where the increase above the spin-only value was ascribed to temperatureindependent paramagnetism. ${ }^{22}$ The magnetic data for $[\mathbf{1 a}] \mathrm{I}_{3} \mathrm{can}$ be fitted to an energetically isolated $S=1 / 2$ ground state with $g=$ 2.03 (fixed), $\theta=-3.8 \mathrm{~K}$, and $\chi_{\mathrm{TIP}}=0.3 \times 10^{-3} \mathrm{~cm}^{3} \mathrm{~mol}^{-1}$ and a small amount of paramagnetic impurity $(S=3 / 2,5.8 \%)$. For $[2 \mathrm{a}] \mathrm{I}_{3}$, the best-fit values are $g=1.99$ and $\theta=-2 \mathrm{~K}$, where the $g$ value is fixed from the electron paramagnetic resonance (EPR) spectrum. The absence of any significant rise in the effective magnetic moment even at $290 \mathrm{~K}$ (for either $[\mathbf{1 a}] \mathrm{I}_{3}$ or $[\mathbf{2 a}] \mathrm{I}_{3}$ ) indicates that there is no significant population of higher rungs on the Heisenberg ladder in the temperature range of these experiments.

Cyclic Voltammetry and EPR Spectroscopy. Cyclic voltammograms of $\mathbf{1 a}, \mathbf{1} \mathbf{b}, \mathbf{2} \mathbf{a}$, and $\mathbf{2} \mathbf{b}$ were recorded in $\mathrm{CH}_{2} \mathrm{Cl}_{2}$ solutions containing $0.1 \mathrm{M}$ tetrabutylammonium perchlorate (TBAP) as the supporting electrolyte using platinum as the working electrode at $25^{\circ} \mathrm{C}$. The potentials are referenced to the saturated calomel electrode (SCE), and the results are summarized in Table 2. The segmented voltammograms (for $\mathbf{1 a}$ and $\mathbf{2 a}$ ) are displayed in Figure 6. 1a exhibits three reversible oxidation waves and one reversible cathodic process at $0.01,0.81,1.31$, and $-1.05 \mathrm{~V}$, respectively. In addition, an irreversible cathodic response at $-1.59 \mathrm{~V}$ was also observed. The one-electron redox processes were confirmed 
Table 1. Selected Bond Distances $(\AA)$, Bond Angles (deg), and Trigonal Twist Angles $(\Theta)$ of $1 \mathrm{a} \cdot \mathrm{CH}_{2} \mathrm{Cl}_{2},[1 \mathrm{a}] \mathrm{I}_{3}, 2 \mathrm{a} \cdot 2 \mathrm{CH}_{2} \mathrm{Cl}_{2}$, and $[2 a]_{3}$

\begin{tabular}{|c|c|c|c|c|c|c|c|c|c|c|}
\hline \multirow[b]{2}{*}{ bond } & \multicolumn{2}{|c|}{ 1a. $\mathrm{CH}_{2} \mathrm{Cl}_{2}$} & \multicolumn{2}{|c|}{$[\mathbf{1 a}] \mathrm{I}_{3}$} & \multirow{2}{*}{$\frac{[\mathbf{1 a}]^{-}}{\text {calcd }}$} & \multicolumn{2}{|c|}{$2 \mathrm{a} \cdot 2 \mathrm{CH}_{2} \mathrm{Cl}_{2}$} & \multicolumn{2}{|c|}{$[2 a]_{3}$} & \multirow{2}{*}{$\frac{[2 \mathrm{a}]^{-}}{\text {calcd }}$} \\
\hline & exptl & calcd & exptl & calcd & & exptl & calcd & exptl & calcd & \\
\hline $\mathrm{M}-\mathrm{N} 1$ & $2.069(2)$ & 2.09 & $2.049(4)$ & 2.08 & 2.05 & $2.1529(17)$ & 2.17 & $2.173(4)$ & 2.17 & 2.17 \\
\hline $\mathrm{M}-\mathrm{N} 3$ & $1.940(2)$ & 2.04 & $1.994(4)$ & 2.05 & 2.05 & $2.0170(17)$ & 2.08 & $1.980(4)$ & 2.09 & 2.05 \\
\hline $\mathrm{M}-\mathrm{N} 4$ & $2.040(2)$ & 2.09 & $2.059(4)$ & 2.08 & 2.09 & $2.1603(17)$ & 2.17 & $2.158(4)$ & 2.17 & 2.17 \\
\hline $\mathrm{M}-\mathrm{N} 6$ & $1.954(2)$ & 2.04 & $2.023(4)$ & 2.05 & 2.09 & $2.0172(17)$ & 2.08 & $2.022(4)$ & 2.09 & 2.05 \\
\hline $\mathrm{M}-\mathrm{N} 7$ & $2.048(2)$ & 2.09 & $2.059(4)$ & 2.08 & 2.13 & $2.1597(17)$ & 2.17 & $2.141(4)$ & 2.17 & 2.17 \\
\hline $\mathrm{M}-\mathrm{N} 9$ & $1.948(2)$ & 2.04 & $1.979(4)$ & 2.05 & 2.06 & $2.0209(17)$ & 2.08 & $2.017(4)$ & 2.09 & 2.05 \\
\hline $\mathrm{N} 2-\mathrm{N} 3$ & $1.345(3)$ & 1.33 & $1.314(5)$ & 1.29 & 1.40 & $1.361(2)$ & 1.34 & $1.383(5)$ & 1.30 & 1.37 \\
\hline N5-N6 & $1.345(3)$ & 1.33 & $1.316(5)$ & 1.29 & 1.33 & $1.356(2)$ & 1.34 & $1.339(6)$ & 1.30 & 1.37 \\
\hline N8-N9 & $1.341(3)$ & 1.33 & $1.334(5)$ & 1.29 & 1.33 & $1.356(2)$ & 1.34 & $1.341(6)$ & 1.30 & 1.37 \\
\hline $\mathrm{N} 1-\mathrm{M}-\mathrm{N} 6$ & $168.15(9)$ & 166.6 & $164.86(14)$ & 166.6 & 167.4 & $161.33(6)$ & 163.1 & $161.60(15)$ & 163.4 & 161.6 \\
\hline $\mathrm{N} 3-\mathrm{M}-\mathrm{N} 7$ & $165.06(8)$ & 166.4 & $167.90(15)$ & 167.0 & 166.7 & $160.92(6)$ & 163.0 & $165.53(15)$ & 163.3 & 161.5 \\
\hline $\mathrm{N} 4-\mathrm{M}-\mathrm{N} 9$ & $165.32(9)$ & 166.7 & $167.24(14)$ & 167.1 & 164.9 & $161.81(7)$ & 162.9 & $160.11(15)$ & 163.5 & 161.6 \\
\hline$\Theta_{1}$ & 39.20 & & 39.84 & & & 32.72 & & 33.17 & & \\
\hline$\Theta_{2}$ & 39.92 & & 38.88 & & & 34.84 & & 36.07 & & \\
\hline$\Theta_{3}$ & 39.30 & & 39.28 & & & 36.09 & & 37.22 & & \\
\hline \multirow[t]{3}{*}{$\rho \mathrm{M} / \mathrm{L}$} & & $2.98 /-0.99$ & & $2.81 /-0.61$ & $2.99 / 0.04$ & & $1.86 /-0.62$ & & $1.46 /-0.16$ & $1.13 /-0.04$ \\
\hline & & -0.99 & & -0.60 & -1.00 & & -0.62 & & -0.16 & -0.04 \\
\hline & & -0.99 & & -0.60 & -1.03 & & -0.62 & & -0.16 & -0.04 \\
\hline$\left\langle S^{2}\right\rangle$ & & 2.48 & & 2.08 & 2.51 & & 1.29 & & 0.87 & 0.79 \\
\hline
\end{tabular}

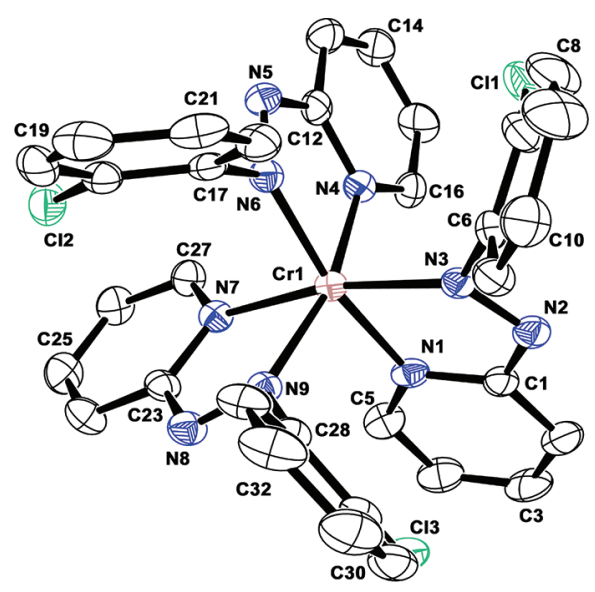

Figure 3. ORTEP representation and atom numbering scheme for complex $[\mathbf{1 a}]^{+}$in $[\mathbf{1 a}] \mathrm{I}_{3}$. Hydrogen atoms are omitted for clarity.

by constant-potential electrolysis for the reversible waves at 0.3 , $1.0,1.5$, and $-1.2 \mathrm{~V}$, respectively. The electron-transfer series for $\mathbf{1 a}$ is displayed in Figure 7. Complex 2a, on the other hand, showed two reversible one-electron waves: one oxidative response at $0.28 \mathrm{~V}$ and a reductive response at $-1.1 \mathrm{~V}$. In addition, an irreversible anodic response at $1.06 \mathrm{~V}$ and a quasi-reversible cathodic response at $-1.81 \mathrm{~V}$ were also noted. The redox potential of the first oxidation process is low, allowing us to isolate the two cationic complexes $[\mathbf{1 a}]_{3}$ and $[\mathbf{2 a}]_{3}$ in a crystalline pure state using $\mathrm{I}_{2}$ as the oxidizing agent. Our attempts to isolate the other redox partners were, however, unsuccessful.

At $120 \mathrm{~K}$, the EPR spectrum of $[\mathbf{1 a}] \mathrm{I}_{3}$ displayed $^{7 \mathrm{a}}$ an axial signal with $g_{\perp}=1.995$ and $g_{\|}=1.993$ having hyperfine couplings

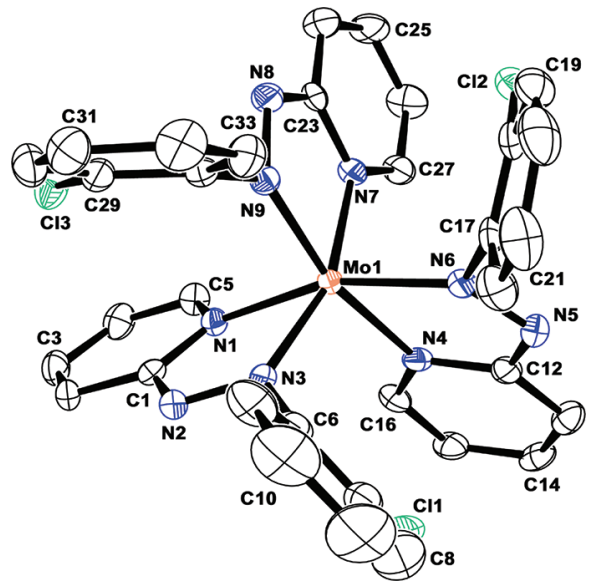

Figure 4. ORTEP representation and atom numbering scheme for complex $[2 \mathbf{a}]^{+}$in $[2 \mathbf{a}] \mathrm{I}_{3}$. Hydrogen atoms are omitted for clarity.

of $A_{\perp}=20 \times 10^{-4} \mathrm{~cm}^{-1}$ and $A_{\|}=7 \times 10^{-4} \mathrm{~cm}^{-1}$, respectively. The hyperfine interactions appear as satellite lines flanking narrow peaks because of coupling of the ${ }^{53} \mathrm{Cr}\left(I={ }^{3} / 2,9.54 \%\right.$ natural abundance) isotope. The monoanion $[\mathbf{1 a}]^{-}$, generated by exhaustive electrolysis, shows a metal-centered axial signal with $g_{\perp}=1.996$ and $g_{\|}=1.991\left(A_{\perp}=19 \times 10^{-4} \mathrm{~cm}^{-1}\right.$ and $A_{\|}=$ $8 \times 10^{-4} \mathrm{~cm}^{-1}$ ) for an $S=1 / 2$ state (Figure $S 6$ in the Supporting Information). The coulometrically generated (at $120 \mathrm{~K}$ ) dication $[\mathbf{1 a}]^{2+}$ is EPR-silent at X band, but the trication $[\mathbf{1 a}]^{3+}$ is EPRactive. Its spectrum at $120 \mathrm{~K}$ (Figure S7 in the Supporting Information) is typical of a $\mathrm{Cr}^{\mathrm{III}} \mathrm{S}=3 / 2$ ground state with signals at $g_{\text {eff, } \perp}=4.75$ and $g_{\text {eff, } \|}=1.98$, due to the $M_{S}= \pm^{1} / 2$ 


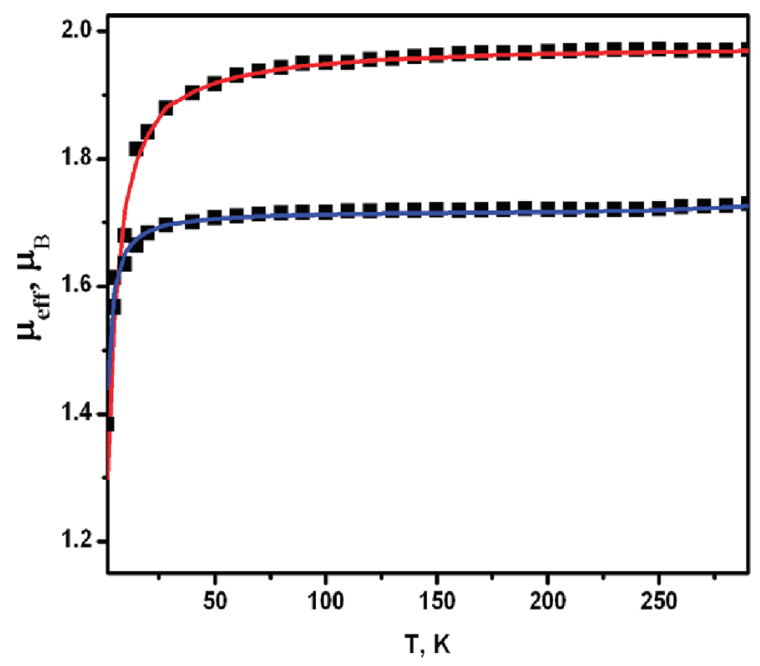

Figure 5. Temperature dependence of the magnetic moment, $\mu_{\mathrm{eff}}\left(\mu_{\mathrm{B}}\right)$, of polycrystalline samples of $[\mathbf{1 a}] \mathrm{I}_{3}$ (black) and $[\mathbf{2 a}] \mathrm{I}_{3}$ (blue). The filled squares represent experimental data, whereas the solid lines represent simulations.

Table 2. Cyclic Voltammetry Data ${ }^{a, b}$ of $1 a, 1 b, 2 a$, and $2 b$

\begin{tabular}{|c|c|c|}
\hline Compound & $\begin{array}{l}\text { oxidation } E_{1 / 2}{ }^{c} \mathrm{~V} \\
\quad\left(\Delta E_{\mathrm{p}}, \mathrm{mV}\right)\end{array}$ & $\begin{array}{c}\text { reduction } E_{1 / 2},{ }^{c} \mathrm{~V} \\
\left(\Delta E_{\mathrm{p}}, \mathrm{mV}\right)\end{array}$ \\
\hline 1a & $0.01(84), 0.81(90), 1.31(85)$ & $-1.05(88),-1.59$ \\
\hline $1 b$ & $0.01(90), 0.79(95), 1.28$ (95) & $-1.09(90),-1.61$ \\
\hline $2 a$ & $0.28(90), 1.06$ & $-1.1(90),-1.81$ \\
\hline $2 b$ & 0.27 (100), 1.01 & $-1.18(85),-1.88$ \\
\hline
\end{tabular}

${ }^{a}$ In a $\mathrm{CH}_{2} \mathrm{Cl}_{2}$ solution, supporting electrolyte $\mathrm{Bu}_{4} \mathrm{NClO}_{4}(0.1 \mathrm{M})$, and reference electrode SCE. ${ }^{b}$ Solute concentration ca. $10^{-3} \mathrm{M} .{ }^{c} E_{1 / 2}=$ $0.5\left(E_{\mathrm{pa}}+E_{\mathrm{pc}}\right)$, where $E_{\mathrm{pa}}$ and $E_{\mathrm{pc}}$ are anodic and cathodic peak potentials, respectively; $\Delta E_{\mathrm{p}}=E_{\mathrm{pa}}-E_{\mathrm{pc}}$; scan rate $=50 \mathrm{mV} \mathrm{s}^{-1}$.

Kramers' doublet with large zero-field splitting $(D>h v)$. A sharp well-resolved peak at $g_{\text {eff }}=5.65$ originates from the $M_{S}= \pm^{3} / 2$ Kramers' doublet, which loses intensity with increasing temperature ( $150 \mathrm{~K}$; inset in Figure S7 in the Supporting Information). Thus, the $\left.\left.\right|^{3} / 2, \pm^{3} / 2\right\rangle$ doublet is the ground state and $D$ is negative. $E / D$ and $D$ have been estimated from Rhombogram for the $S=3 / 2$ system, and the values are $\sim 0.1$ and $\sim-3 \mathrm{~cm}^{-1}$, respectively. For the molybdenum complexes, both the monocationic and monoanionic species are EPR-active and showed metal-centered axial signals with $g_{\|}=1.998$ and $g_{\perp}=2.010$ for $[2 \mathrm{a}]^{+}$and $g_{\|}=1.995$ and $g_{\perp}=2.001$ for $[2 \mathrm{a}]^{-}$, respectively, signifying $S=1 / 2$ electronic ground states in both cases (Figure S8 in the Supporting Information). ${ }^{23}$ The EPR-simulated parameters for $S=1 / 2$ complexes are given in Table 3.

UV-Near-IR (NIR) Spectroelectrochemistry. Electronic spectra of the chromium complexes $1 \mathrm{a},[\mathbf{1} \mathbf{a}]_{3},[\mathbf{1 a}]^{2+}$, and $[\mathbf{1} \mathbf{a}]^{3+}$ are displayed in Figure 8. The spectra for $2 \mathrm{a},[2 \mathrm{a}] \mathrm{I}_{3}$, and $[2 \mathrm{a}]^{-}$ are collected in Figure 9. The dication, trication, and monoanion were generated electrochemically in $\mathrm{CH}_{2} \mathrm{Cl}_{2}$ using TBAP $(0.1 \mathrm{M})$ as the supporting electrolyte at $-5{ }^{\circ} \mathrm{C}$. The data are summarized in Table 4. The neutral and tricationic chromium complexes show weak features in the region $600-800 \mathrm{~nm}$ that are typical of a $\mathrm{Cr}^{\mathrm{III}}$ ion. The mono- and dication also have a broad absorption band in the NIR region $(\sim 1500 \mathrm{~nm})$ that has previously been assigned as an interligand charge-transfer band. ${ }^{7 \mathrm{a}, \mathrm{b}}$ In the molybdenum

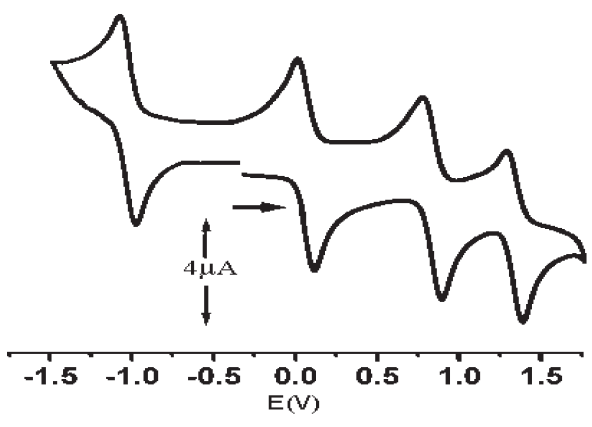

(a)

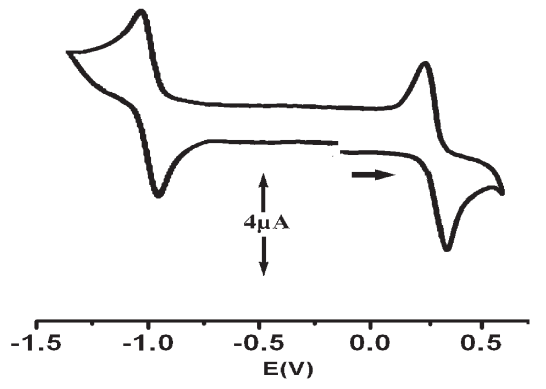

(b)

Figure 6. Segmented cyclic voltammograms of 1a (a) and 2a (b) in $\mathrm{CH}_{2} \mathrm{Cl}_{2}$.

analogue, the near-IR band is conspicuously absent, but the cation shows a broad absorption centered on $800 \mathrm{~nm}$ containing two overlapping peaks. ${ }^{\text {a }}$

\section{DISCUSSION}

Electronic Structures of Chromium Compounds 1a, [1a ${ }^{+}$, and $[1 \mathrm{a}]^{-}$. Optimized structural parameters for the computed ground states of the $\mathbf{1 a},[\mathbf{1} \mathbf{a}]^{+}$, and $[\mathbf{1 a}]^{-}\left(M_{S}=0,1 / 2\right.$, and $1 / 2$, respectively) along with net spin densities are collected in Table 1. Plots of the net spin densities are shown in Figure 10 (isosurface contour $0.006 \mathrm{e} \mathrm{au}^{-3}$ ). The optimized $\mathrm{N}-\mathrm{N}$ bond length of $1.33 \AA$ for the broken-symmetry $\left(M_{S}=0\right)$ ground state of the neutral species is marginally shorter than that obtained from the X-ray experiment $[1.342(3) \AA]$, but the elongation relative to the free ligand [calcd $d(\mathrm{~N}-\mathrm{N})=1.24 \AA$ ] is well reproduced (Scheme 1). Net spin densities of 2.98 and -0.99 on the metal and each ligand, respectively, in $\mathbf{1}$ a are emphatically in favor of a ligand-radical formulation, with the $\mathrm{Cr}^{\mathrm{III}}$ center antiferromagnetically coupled to three ligand radicals (a full spin-density plot is shown in Figure 10). The ferromagnetically coupled high-spin $(S=3)$ state lies $0.84 \mathrm{eV}$ higher in energy, corresponding to a $J$ value of $-706 \mathrm{~cm}^{-1}\left[\hat{H}=-2 J\left(\hat{S}_{\mathrm{Cr}} \cdot \hat{S}_{\mathrm{Lig}}\right)\right]$. This relatively strong exchange coupling is fully consistent with the observed diamagnetism of the compound and also the substantial overlaps, $S$, between the corresponding orbitals (0.16-0.52; Figure S10 in the Supporting Information).

One-electron oxidation of 1 a generates $[1 \mathbf{a}]^{+}$in a brokensymmetry doublet ground state. The spin density at the metal is similar in the cation and the neutral species $\left(\rho_{\mathrm{Cr}}=2.81\right.$; Table 1 and Figure 10), offering a strong indication that the oxidation is a ligand-based redox event. The structural impact of the oxidation is therefore localized entirely in the ligand array, where the $\mathrm{N}=\mathrm{N}$ bonds contract by $0.04 \AA$ (cf. $\sim 0.03 \AA$ in the X-ray data). The suitability of time-dependent DFT (TD-DFT) based on a 


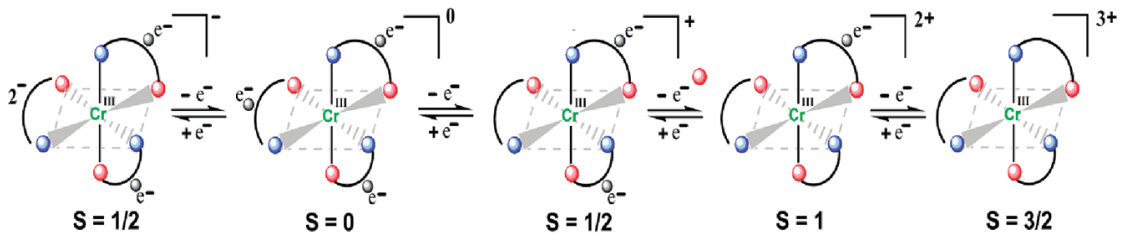

$O=N(a z o) O=N(p y)$

Figure 7. Electron-transfer series for $\mathbf{1 a}$.

Table 3. Simulated EPR Spin-Hamiltonian Parameters $g$ and $A\left(\times 10^{-4} \mathrm{~cm}^{-1}\right)$ for $S=1 / 2$ Complexes

\begin{tabular}{ccccc} 
compound & $g_{\|}$ & $g_{\perp}$ & $A_{\|}$ & $A_{\perp}$ \\
{$[\mathbf{1 a}] \mathrm{I}_{3}$} & 1.993 & 1.995 & 7 & 20 \\
{$[\mathbf{1 a}]^{-}$} & 1.991 & 1.996 & 8 & 19 \\
{$[\mathbf{2 a}] \mathrm{I}_{3}$} & 1.998 & 2.010 & 60 & 22 \\
{$[\mathbf{2 a}]^{-}$} & 1.995 & 2.001 & 65 & 23 \\
\hline
\end{tabular}

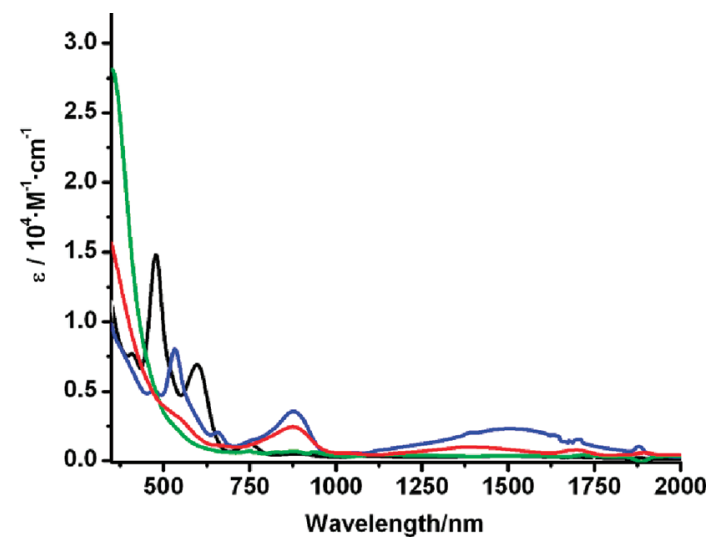

Figure 8. Electronic spectra of $1 \mathrm{a}$ (black), $[\mathbf{1 a}] \mathrm{I}_{3}$ (blue), $[\mathbf{1 a}]^{2+}$ (red), and $[\mathbf{1 a}]^{3+}$ (green) in $\mathrm{CH}_{2} \mathrm{Cl}_{2}$.

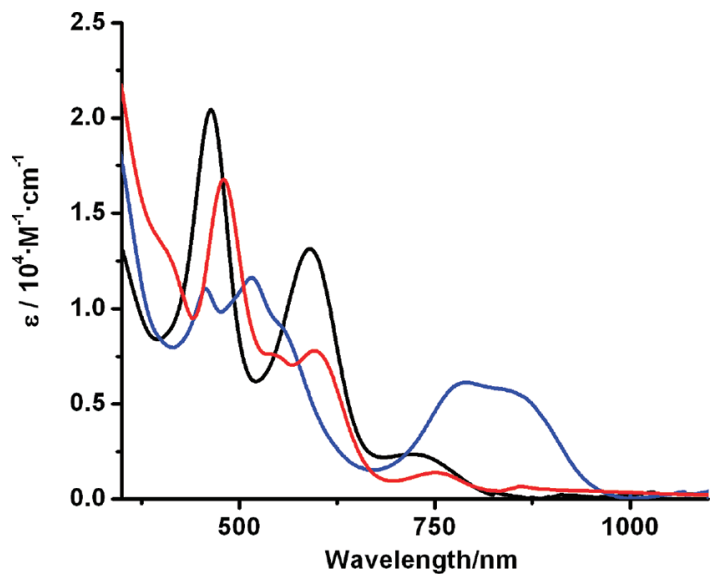

Figure 9. Electronic spectra of $\mathbf{2 a}$ (black), $[\mathbf{2 a}] \mathrm{I}_{3}$ (blue), and $[\mathbf{2 a}]^{-}$ (red) in $\mathrm{CH}_{2} \mathrm{Cl}_{2}$.

broken-symmetry ground state has been debated, but, nevertheless, excellent agreement between computed ligand-ligand
Table 4. UV-NIR Data ${ }^{a}$

$\begin{array}{cc}\text { compound } & \lambda_{\max } \mathrm{nm}\left(\varepsilon, \mathrm{M}^{-1} \mathrm{~cm}^{-1}\right) \\ {[\mathbf{1 a}]} & 600(6910), 480(15010), 415 \mathrm{sh} \\ {[\mathbf{1 a}] \mathrm{I}_{3}} & 1505(2380), 875(3660), 660 \mathrm{sh}, 530(8140), 480 \mathrm{sh} \\ {[\mathbf{1 a}]^{2+}} & 1405(1055), 875(2630), 660 \mathrm{sh}, 530(4600) \\ {[\mathbf{1 a}]^{3+}} & 880(1430), 530 \mathrm{sh} \\ {[\mathbf{2 a}]} & 725(2490), 590(13240), 464(20330) \\ {[\mathbf{2 a}]_{3}} & 800(5840), 558 \mathrm{sh}, 519(11610), 455(10870) \\ {[\mathbf{2 a}]^{-}} & 745(3260), 585(1000), 460(18120) \\ { }^{a} \mathrm{In}_{\mathrm{CH}_{2} \mathrm{Cl}_{2}, 5 \times 10^{-5} \mathrm{M} .}\end{array}$

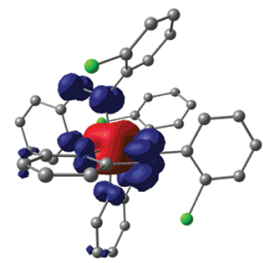

$[1 \mathrm{a}]^{+}$

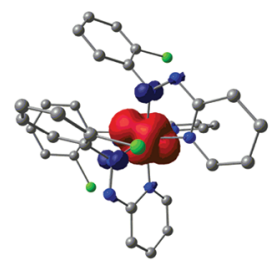

[2a $]^{+}$

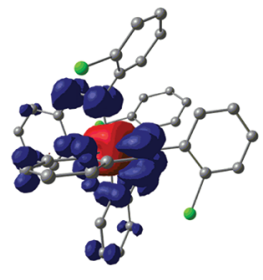

1a

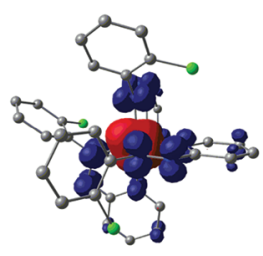

2a

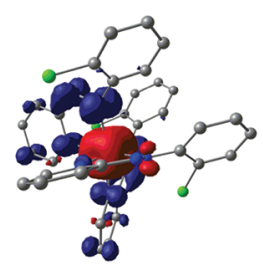

$[1 \mathrm{a}]^{-}$

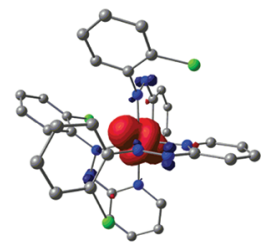

$[2 \mathrm{a}]^{-}$
Figure 10. Net spin densities of $[\mathbf{1 a}]^{+}, \mathbf{1 a},[\mathbf{1 a}]^{-},[\mathbf{2 a}]^{+}, \mathbf{2 a}$, and $[\mathbf{2 a}]^{-}$. Isosurface $=0.006 \mathrm{e} \mathrm{au}^{-3}$.

charge-transfer (LLCT) excitation energies and features in the NIR spectrum of closely related complexes has been reported. ${ }^{24}$ In the case of $[\mathbf{1 a}]^{+}$, we compute an absorption feature at $0.7 \mathrm{eV}$ $(1760 \mathrm{~nm})$ corresponding to a transition within the $\mathrm{N}=\mathrm{N} \pi^{*}$ array, in excellent agreement with the weak feature at $\sim 1500 \mathrm{~nm}$ assigned to a LLCT band in the NIR spectrum of $[\mathbf{1 a}]^{+}$(Figure S9 in the Supporting Information). The ferromagnetically coupled counterpart of the ground state of $[\mathbf{1 a}]^{+}$with $M_{S}=5 / 2$ lies 0.88 $\mathrm{eV}$ higher in energy, corresponding to a $J$ value of $-1052 \mathrm{~cm}^{-1}$. Higher states on the Heisenberg ladder are therefore clearly inaccessible in the temperature range of the magnetic measurements. One-electron reduction to form the anionic species $[\mathbf{1 a}]^{-}$also results in negligible changes in the spin density at the metal $\left(\rho_{\mathrm{Cr}}=\right.$ 2.99; Figure 10) and is therefore unambiguously ligand-based. A broader survey of redox isomers (see Figures S11-S14 in the Supporting Information) indicates that the $\mathrm{Cr}^{\mathrm{III}}$ ion remains 


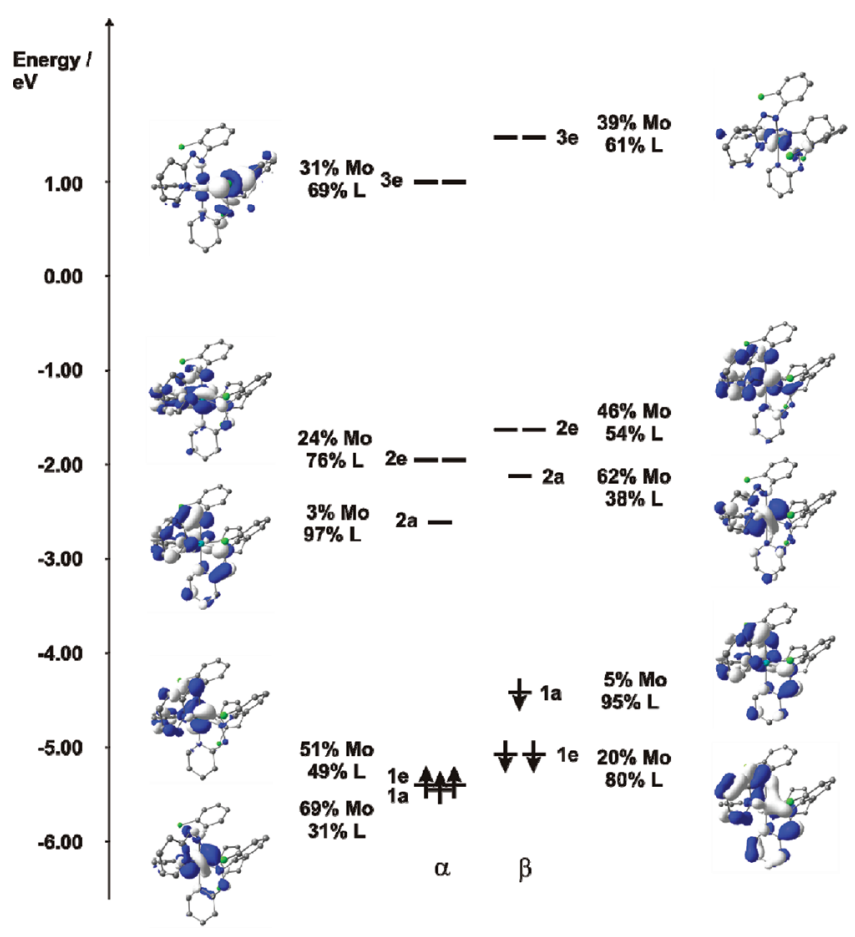

Figure 11. Frontier Kohn-Sham orbitals for 2a.

invariant across the entire series $[\mathbf{1 a}]^{-/ 0 /+/ 2+/ 3+}$, with all redox events localized on the ligands. As a result, the $\mathrm{N}=\mathrm{N}$ bond lengths contract upon successive oxidation, and those in the trication $\left(M_{S}=3 / 2\right)$ approach the values for the free ligand $(\sim 1.24 \AA)$. The robustness of the $\mathrm{Cr}^{\mathrm{III}}$ center results largely from the very high exchange energies associated with the $\mathrm{t}_{2 \mathrm{~g}}{ }^{3}$ configuration.

Electronic Structures of Molybdenum Compounds 2a, $[2 \mathrm{a}]^{+}$, and $[2 \mathrm{a}]^{-}$. Turning to the molybdenum analogues, a comparison of the optimized geometry of $\mathbf{2 a}$ with that of $\mathbf{1 a}$ (Table 1) confirms that the more pronounced elongation of the $\mathrm{N}=\mathrm{N}$ bond in the molybdenum systems is well reproduced, as are the key trends in the $\mathrm{M}-\mathrm{N}$ bond lengths. Thus, while all $\mathrm{Mo}-\mathrm{N}$ bonds are longer than their $\mathrm{Cr}-\mathrm{N}$ counterparts, the elongation is more prominent in $\mathrm{M}-\mathrm{N}_{\mathrm{py}}(\Delta \mathrm{M}-\mathrm{N}=0.10 \AA)$ than in $\mathrm{M}-\mathrm{N}_{\mathrm{azo}}(\Delta \mathrm{M}-\mathrm{N}=0.06 \AA)$. The frontier Kohn-Sham orbitals of $2 \mathrm{a}$ are shown in Figure 11, and their compositions, along with those of $[\mathbf{2 a}]^{+}$and $[\mathbf{2 a}]^{-}$, are collected in Table 6 . The orbitals of $2 \mathrm{a}$ show the symmetry breaking typical of a metalradical complex, with the spin- $\alpha$ and spin- $\beta$ components of each orbital localized in different regions of the molecule. Thus, the three occupied spin- $\alpha$ orbitals $[1 \mathrm{a}(\alpha)$ and $1 \mathrm{e}(\alpha)]$ are polarized toward the metal center and lie $\sim 3.0 \mathrm{eV}$ below their vacant spin$\beta$ counterparts $[2 \mathrm{a}(\beta)$ and $2 \mathrm{e}(\beta)]$. Conversely, the three singly occupied spin- $\beta$ orbitals, $[1 \mathrm{a}(\beta)$ and $1 \mathrm{e}(\beta)]$ are linear combinations of $\mathrm{N}=\mathrm{N} \pi^{*}$ orbitals $(>80 \% \mathrm{~L})$ and lie only $\sim 2.0 \mathrm{eV}$ below their vacant spin- $\alpha$ counterparts $[2 \mathrm{a}(\alpha)$ and $2 \mathrm{e}(\alpha)]$. The smaller exchange splitting in the ligand-based orbitals reflects the more diffuse nature of the singly occupied orbitals. The compositions of the $1 \mathrm{a}(\alpha / \beta)$ and $1 \mathrm{e}(\alpha / \beta)$ orbitals also reveal a distinct anisotropy, in so much as the symmetry breaking is much less pronounced in the degenerate e orbitals, $1 \mathrm{e}(\alpha)$ and $1 \mathrm{e}(\beta)(\mathrm{Mo}: \mathrm{L}=$ $51: 49$ and 20:80) than in $1 \mathrm{a}(\alpha)$ and $1 \mathrm{a}(\beta)(69: 31$ and 5:95). This anisotropy within the octahedral $t_{2 g}$ set has been noted by Ackermann and co-workers ${ }^{15}$ and stems from the presence of only a single orbital of $\pi$ symmetry on each of the nitrogen-donor atoms of the $\mathrm{N}=\mathrm{N}$ unit. The result is that, despite sharing the same symmetry $(\mathrm{a})$, the Mo $\mathrm{d}_{z^{2}}$ orbital ( $z$ defined here as the trigonal axis) is poorly oriented to overlap with the totally symmetric linear combination of $\mathrm{N}=\mathrm{N} \pi^{*}$ orbitals. This distinction between the orbitals of a and e symmetry is further emphasized by the overlap $(S)$ between the corresponding orbitals (Figure 12), which is 0.36 for the a-symmetric pair but 0.89 for the e set.

In the chromium system $1 \mathrm{a}$, the assignment of the oxidation state was unambiguous: the spin-density pattern, $\rho_{\mathrm{M}}, \rho_{\mathrm{L}} \approx+3.0$, -1.0 is clearly consistent only with a $\left[\mathrm{Cr}^{\mathrm{III}}\left(\mathrm{L}^{\bullet-}\right)_{3}\right]$ formulation. In cases such as $\mathbf{2 a}$, where the radical character is not so pronounced, the oxidation state is more open to debate because it inevitably involves the somewhat arbitrary assignment of the shared electron density to one center or the other. In the limit of complete symmetry breaking (i.e., where the spatial parts of the two spin components are quite distinct), as they are in $1 \mathbf{a}\left(\rho_{\mathrm{M}}, \rho_{\mathrm{L}}=+3.0\right.$, $-1.0)$, a $\left[\mathrm{Mo}^{\mathrm{III}}\left\{\mathrm{L}_{3}\right\}^{3-}\right]$ formulation is clearly appropriate. However, when $1 \mathrm{e}(\alpha)$ and $1 \mathrm{e}(\beta)$ are identical, the limiting spin densities of $\rho_{\mathrm{M}}, \rho_{\mathrm{L}}=+1.0,-0.33$ could correspond to any point on a $\left[\mathrm{Mo}^{\mathrm{III}}\left\{\mathrm{L}_{3}\right\}^{3-}\right] \leftrightarrow\left[\mathrm{Mo}^{\mathrm{IV}}\left\{\mathrm{L}_{3}\right\}^{4-}\right] \leftrightarrow\left[\mathrm{Mo}^{\mathrm{V}}\left\{\mathrm{L}_{3}\right\}^{5-}\right]$ continuum, depending on whether the four electrons are viewed as being primarily ligand- or metal-based. We note that localization of the occupied $1 \mathrm{a}(\alpha)$ orbital on the metal center precludes a $\left[\mathrm{Mo}^{\mathrm{VI}}\left\{\mathrm{L}_{3}\right\}^{6-}\right]$ formulation. The computed values of +1.86 and -0.66 for 2 a lie almost exactly midway between the two limits identified above, indicating substantial but not complete symmetry breaking in the $1 \mathrm{e}(\alpha / \beta)$ orbitals. We return to the question of the oxidation state following a discussion of the related cation and anion.

Oxidation of $2 \mathbf{a}$ generates $[\mathbf{2 a}]^{+}$in an $M_{S}=1 / 2$ ground state, and the redox event can again be considered, at least to first order, as ligand-based because the redox-active orbital, $1 \mathrm{a}(\beta)$, remains strongly localized on the ligand array (96\%). However, the changes in the spin density at molybdenum (1.46 vs 1.86 in $2 \mathrm{a}$; see Figure 10$)^{25}$ indicate that the metal is far from innocent, and the compositions of the orbitals in Table 6 confirm a substantial redox-induced redistribution of the charge. Compared to $\mathbf{2 a}$, the occupied spin- $\beta$ components of the $1 \mathrm{e}$ orbital are now much more evenly distributed over Mo (32\%) and L (68\%) and are spatially rather more similar to their spin- $\alpha$ counterparts $(45 \%$ Mo and $41 \% \mathrm{~L})$. The equalization of the spatial parts of $1 \mathrm{e}(\alpha)$ and $1 \mathrm{e}(\beta)$ is reflected in a further increase in the overlap of the corresponding orbitals ( $S=0.97$ vs 0.89 in $2 \mathrm{a}$ ). These trends can be interpreted in terms of the redox-induced stabilization of the ligand-based orbitals resulting from removal of the electron in $1 \mathrm{a}(\beta)$, which enhances back-bonding from molybdenum via the orthogonal degenerate e orbitals. Symmetry breaking is therefore less pronounced and metal and ligand character more evenly distributed among $1 \mathrm{e}(\alpha / \beta)$ and $2 \mathrm{e}(\alpha / \beta)$.

We can again use the contrasting limits of complete symmetry breaking and complete delocalization of the electrons in the $1 \mathrm{e}$ orbitals to define the possible range of spin densities. In the case that the spin components of the le orbital have identical spatial components, the limiting net spin densities would be +1.0 and 0.0. Complete symmetry breaking [i.e., localization of $1 \mathrm{e}(\alpha)$ and $1 \mathrm{e}(\beta)$ on metal and ligand, respectively], in contrast, would generate limiting spin densities of +3.0 and -0.66 , very close to the values computed for $[1 \mathrm{a}]^{+}$. The computed values of +1.46 and -0.16 for $[2 a]^{+}$clearly lie much closer to the former limit, reflecting the pronounced back-bonding in this case.

The net spin densities for the anion $[2 \mathrm{a}]^{-}\left(M_{S}=1 / 2\right.$ ground state) show striking similarities to the cation $\left(\rho_{\mathrm{M}}, \rho_{\mathrm{L}}=+1.13\right.$, 
Table 5. Crystallographic Data of $1 \mathrm{a} \cdot \mathrm{CH}_{2} \mathrm{Cl}_{2},[1 \mathrm{a}] \mathrm{I}_{3}, 2 \mathrm{a} \cdot 2 \mathrm{CH}_{2} \mathrm{Cl}_{2}$, and $[2 \mathrm{a}] \mathrm{I}_{3}$

\begin{tabular}{|c|c|c|c|c|}
\hline & {$[\mathbf{1 a}] \cdot \mathrm{CH}_{2} \mathrm{Cl}_{2}$} & {$[\mathbf{1 a}]_{3}$} & {$[2 \mathrm{a}] \cdot 2 \mathrm{CH}_{2} \mathrm{Cl}_{2}$} & {$[2 \mathrm{a}] \mathrm{I}_{3}$} \\
\hline empirical formula & $\mathrm{C}_{34} \mathrm{H}_{26} \mathrm{Cl}_{5} \mathrm{CrN}_{9}$ & $\mathrm{C}_{33} \mathrm{H}_{24} \mathrm{Cl}_{3} \mathrm{CrI}_{3} \mathrm{~N}_{9}$ & $\mathrm{C}_{35} \mathrm{H}_{28} \mathrm{Cl}_{7} \mathrm{MoN}_{9}$ & $\mathrm{C}_{33} \mathrm{H}_{24} \mathrm{Cl}_{3} \mathrm{I}_{3} \mathrm{MoN}_{9}$ \\
\hline mol mass & 789.89 & 1085.66 & 918.75 & 1129.60 \\
\hline temperature $(\mathrm{K})$ & $150(2)$ & $150(2)$ & $150(2)$ & $150(2)$ \\
\hline cryst syst & triclinic & monoclinic & monoclinic & monoclinic \\
\hline space group & $P \overline{1}$ & $P 21 / n$ & $P 21 / c$ & $P 21 / n$ \\
\hline$a(\AA)$ & $9.9804(6)$ & $14.205(5)$ & $9.8375(3)$ & $10.0086(11)$ \\
\hline$b(\AA)$ & $10.1877(7)$ & $16.937(5)$ & $32.0144(8)$ & $19.211(2)$ \\
\hline$c(\AA)$ & $18.9810(12)$ & $16.102(5)$ & $12.0829(3)$ & $19.417(2)$ \\
\hline$\alpha(\mathrm{deg})$ & $79.0880(10)$ & 90.0 & 90.0 & 90.0 \\
\hline$\beta(\mathrm{deg})$ & $78.4510(10)$ & $99.699(5)$ & $100.0880(10)$ & $92.017(2)$ \\
\hline$\gamma(\operatorname{deg})$ & $64.2980(10)$ & 90.0 & 90.0 & 90.0 \\
\hline$V\left(\AA^{3}\right)$ & $1692.27(19)$ & $3819(2)$ & $3746.58(17)$ & $3731.0(7)$ \\
\hline Z & 2 & 4 & 4 & 4 \\
\hline$D_{\text {calcd }}\left(\mathrm{g} \mathrm{cm}^{-3}\right)$ & 1.550 & 1.888 & 1.629 & 2.011 \\
\hline cryst dimens (mm) & $0.18 \times 0.24 \times 0.30$ & $0.16 \times 0.18 \times 0.24$ & $0.18 \times 0.20 \times 0.32$ & $0.20 \times 0.24 \times 0.30$ \\
\hline$\theta$ range for data colln ( $\mathrm{deg})$ & $1.1-25.0$ & $1.8-25.4$ & $1.3-25.0$ & $1.5-25.0$ \\
\hline GOF & 1.06 & 1.07 & 1.04 & 1.05 \\
\hline reflns collected & 16029 & 34388 & 44121 & 34967 \\
\hline unique reflns & 5954 & 6967 & 6600 & 6567 \\
\hline largest diff between peak and hole $\left(\mathrm{e} \AA^{-3}\right)$ & $1.02,-0.77$ & $1.61,-1.31$ & $0.46,-0.39$ & $0.95,-1.03$ \\
\hline$R_{\text {int }}$ & 0.031 & 0.058 & 0.032 & 0.050 \\
\hline final $R$ indices $[I>2 \sigma(I)]$ & $\mathrm{R} 1=0.0388, \mathrm{wR} 2=0.1084$ & $\mathrm{R} 1=0.0396, \mathrm{wR} 2=0.1138$ & $\mathrm{R} 1=0.0254, \mathrm{wR} 2=0.0621$ & $\mathrm{R} 1=0.0352, \mathrm{wR} 2=0.0849$ \\
\hline
\end{tabular}

-0.04 vs $+1.46,-0.16$; see also Figure 10$)$ and are quite different from those of the neutral species $\left(\rho_{\mathrm{M}}, \rho_{\mathrm{L}}=+1.86,-0.66\right)$. The Kohn-Sham orbital compositions summarized in Table 6 confirm that the redox-active orbital is again the totally symmetric ligand-based combination, in this case the spin- $\alpha$ component $2 \mathrm{a}(\alpha)$ and that this orbital remains almost entirely ligand-based (96\% L) in the anion. The degree of symmetry breaking in the occupied 1e orbitals is again lower than that in the neutral species $[1 \mathrm{e}(\alpha), 35 \% \mathrm{Mo}, 65 \% \mathrm{~L} ; 1 \mathrm{e}(\beta), 27 \% \mathrm{Mo}, 73 \% \mathrm{~L}]$, and the overlap of the corresponding orbitals approaches unity $(S=$ $0.99)$. The reduced molybdenum character in the $1 \mathrm{e}(\alpha)$ orbital (relative to $2 \mathrm{a}$ ) is offset by an increase in the vacant $2 \mathrm{e}(\alpha)$ orbital ( $38 \%$ Mo vs $24 \%$ in $2 a$ ), indicative of more effective back-bonding in the anionic case.

The conclusion that a primarily ligand-based oxidation process to form $\left[2 \mathrm{a}^{+}\right]$should induce further transfer of the electron density from metal to ligand via a back-bonding mechanism is intuitive and can readily be rationalized on the basis of the stabilization of the ligand $\pi^{*}$ manifold relative to the metal d orbitals. That a one-electron reduction should cause the same effect is somewhat counterintuitive, as we might expect a destabilization of the ligand $\pi^{*}$ manifold to reduce the effectiveness of the backbonding pathway. However, while one-electron oxidation and oneelectron reduction clearly have very different effects on the total electron density at the ligand, both serve to reduce the net spin density and therefore, by extension, the exchange splitting between the occupied spin- $\beta$ and vacant spin- $\alpha$ components of the ligand $\pi^{*}$ manifold. The reduction in the spin density that accompanies either redox event therefore enhances the ability of the ligand array to both donate electron density to and accept electron density from the metal through the e orbitals, where overlap is effective. In this context, the neutral system emerges as the outlier in the series $[\mathbf{2} \mathbf{a}]^{+}, \mathbf{2 a}$, and $[\mathbf{2 a}]^{+}$because the half-filled $\left(\mathrm{N}=\mathrm{N} \pi^{*}\right)^{3}$
Table 6. Compositions of the Frontier Kohn-Sham Orbitals for $[2 \mathrm{a}]^{+}, 2 \mathrm{a}$, and $[2 \mathrm{a}]^{-a}$

\begin{tabular}{|c|c|c|c|c|c|c|}
\hline \multirow[b]{2}{*}{$\mathrm{MO}$} & \multicolumn{2}{|c|}{$[2 a]^{+}$} & \multicolumn{2}{|c|}{$2 a$} & \multicolumn{2}{|c|}{$[2 \mathrm{a}]^{-}$} \\
\hline & Mo & $\mathrm{L}$ & Mo & $\mathrm{L}$ & Mo & $\mathrm{L}$ \\
\hline $3 \mathrm{e}(\beta)$ & 48 & 52 & 39 & 61 & 34 & 66 \\
\hline $3 \mathrm{e}(\alpha)$ & 56 & 44 & 31 & 69 & 31 & 69 \\
\hline $2 \mathrm{e}(\beta)$ & 43 & 57 & 46 & 54 & 41 & 59 \\
\hline $2 \mathrm{a}(\beta)$ & 65 & 35 & 62 & 38 & 58 & 42 \\
\hline $2 \mathrm{e}(\alpha)$ & 30 & 70 & 24 & 76 & 38 & 62 \\
\hline $2 \mathrm{a}(\alpha)$ & 2 & 98 & 3 & 97 & 4 & 96 \\
\hline $\mathrm{la}(\beta)$ & 4 & 96 & 5 & 95 & 9 & 91 \\
\hline le $(\beta)$ & 32 & 68 & 20 & 80 & 27 & 73 \\
\hline $1 \mathrm{e}(\alpha)$ & 49 & 51 & 51 & 49 & 35 & 65 \\
\hline $\mathrm{la}(\alpha)$ & 69 & 31 & 69 & 31 & 68 & 32 \\
\hline
\end{tabular}

${ }^{a}$ The horizontal line indicates the HOMO-LUMO gap in each case.

shell makes the ligand array unusually resistant to the loss or gain of further electron density from the metal.

Throughout the previous paragraphs, we have avoided an assignment of oxidation states to the molybdenum centers, beyond noting that the neutral species lies somewhere along a continuum linking the three resonance structures $\left[\mathrm{Mo}^{\mathrm{III}}\left\{\mathrm{L}_{3}\right\}^{3-}\right] \leftrightarrow\left[\mathrm{Mo}^{\mathrm{IV}}\left\{\mathrm{L}_{3}\right\}^{4-}\right] \leftrightarrow$ $\left[\mathrm{MoV}\left\{\mathrm{L}_{3}\right\}^{5-}\right]$. The redox-active orbital is almost entirely ligand-based and therefore does not have any first-order impact on the physical oxidation state of the metal. The assignment therefore rests on whether the four electrons in the 1e orbitals are allocated to the metal or ligand in each case. In the anion $[2 \mathbf{a}]^{-}$, $\mathrm{le}(\alpha)$ and $\mathrm{le}(\beta)$ are both strongly localized on the ligand $(65 \%$ 


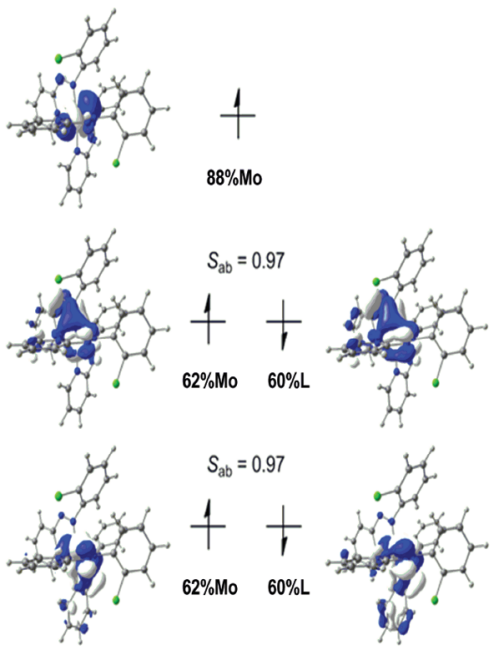

$\left[\mathrm{MoL}_{3}\right]^{+}$
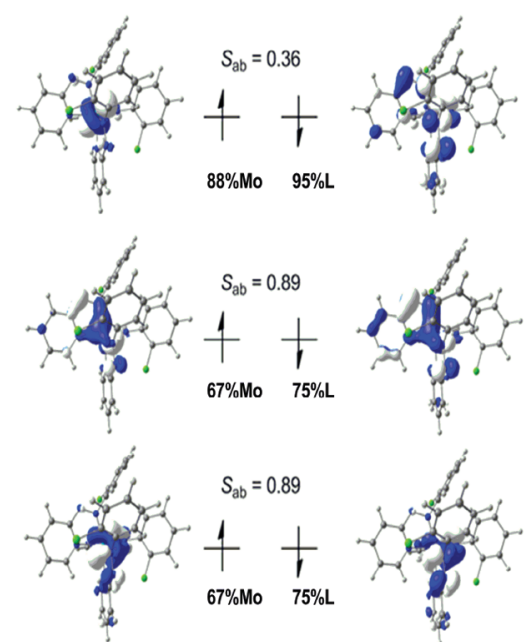

$\left[\mathrm{MoL}_{3}\right]^{0}$
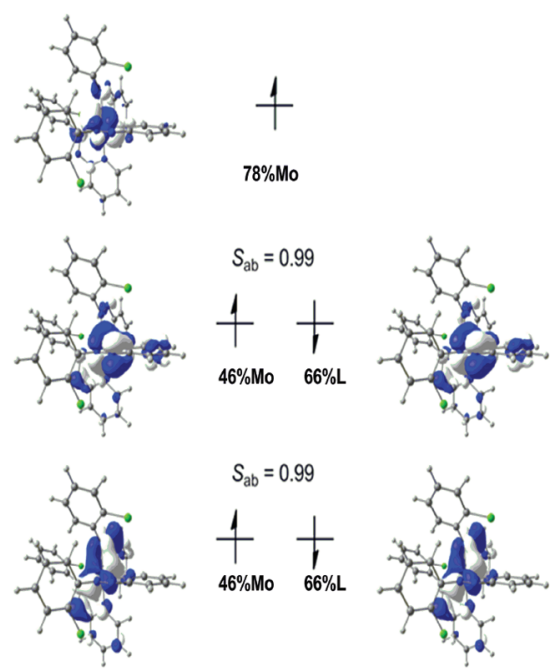

$\left[\mathrm{MoL}_{3}\right]^{-}$

Figure 12. Corresponding orbitals for $2 a,[2 a]^{+}$, and $[2 a]^{-}$.

and $73 \%$, respectively), and so a limiting $\mathrm{Mo}^{\mathrm{V}}$ form seems most realistic. The same is true of the cation $[2 \mathrm{a}]^{+}$, although in this case, the localization of the $1 \mathrm{e}(\alpha)$ orbitals on $\mathrm{L}$ is less clear-cut (49:51). Both cation and anion therefore appear to lie toward the $\mathrm{Mo}$ end of the $\left[\mathrm{Mo}^{\mathrm{III}}\left\{\mathrm{L}_{3}\right\}^{3-}\right] \leftrightarrow\left[\mathrm{Mo}^{\mathrm{IV}}\left\{\mathrm{L}_{3}\right\}^{4-}\right] \leftrightarrow\left[\mathrm{Mo}^{\mathrm{V}}\left\{\mathrm{L}_{3}\right\}^{5-}\right]$ spectrum.

In neutral $2 \mathrm{a}$, the process is further complicated by the symmetry breaking in the le orbital: the spin- $\beta$ component is substantially localized on the ligand, while the spin- $\alpha$ counterpart is delocalized over both the metal and ligand (51:49). We noted above that the limit of complete symmetry breaking would correspond to a $\left[\mathrm{Mo}^{\mathrm{III}}\left\{\mathrm{L}_{3}\right\}^{3-}\right]$ situation, comparable to $\left[\mathrm{Cr}^{\mathrm{III}}\left\{\mathrm{L}_{3}\right\}^{3-}\right]$ (1a). The net spin densities of $2 \mathrm{a}$ are clearly far from this limit, but nevertheless there is a distinct shift to the left in the continuum, with more ligand-radical character relative to either $[\mathbf{2} \mathbf{a}]^{+}$or $[\mathbf{2 a}]^{-}$. The presence of a half-filled $\left(\pi^{*}\right)^{3}$ shell in the neutral case appears to confer a degree of stability on the ligand array, blocking further electron transfer from the metal via back-bonding.

\section{CONCLUSIONS}

We have established the concepts of redox noninnocent behavior in the ligand 2-(arylazo)pyridine and its ability to form metalstabilized azo-anion-radical complexes when reacted with electron-rich metal carbonyls via intramolecular electron exchange. In this paper, we have revisited earlier work by Ackermann et al. with the aim of fully characterizing the accessible redox series for both chromium and molybdenum. From a combination of structural and spectroscopic investigations and DFT calculations, it has been possible to unequivocally establish the electronic structure of the neutral chromium complex $\left[\mathrm{Cr}(\mathrm{L})_{3}\right]^{0}$. It contains a high-spin chromic ion $\left(S_{\mathrm{Cr}}=3 / 2\right)$ coupled to three ligand-radical anions, leading to an $S=0$ ground state, and is essentially identical with the well-characterized neutral chromium complexes with catecholate ligands. Instances of isolation and structural characterization of the chromium complexes of three radical ligands are rare in the literature. The four redox events that connect the electron-transfer series $\left[\mathrm{Cr}(\mathrm{L})_{3}\right]^{n}(n=3+, 2+, 1+, 0$, $1-)$ correspond to entirely ligand-based redox processes, with the central chromium ion remaining in the III oxidation state throughout. The electronic structure of the molybdenum systems is more complex because of extensive mixing of metal- and ligandbased orbitals of e symmetry. The three redox isomers $\left[\mathrm{Mo}(\mathrm{L})_{3}\right]^{n}$ $(n=1+, 0,1-)$ lie on a continuum connecting the resonance forms $\left[\mathrm{Mo}^{\mathrm{III}}\left\{\mathrm{L}_{3}\right\}^{(3-n)-}\right] \leftrightarrow\left[\mathrm{Mo}^{\mathrm{IV}}\left\{\mathrm{L}_{3}\right\}^{(4-n)-}\right] \leftrightarrow\left[\mathrm{Mo}^{\mathrm{V}_{2}}\left\{\mathrm{~L}_{3}\right\}^{(5-n)-}\right]$, with the orbital compositions and spin densities being most consistent with the higher-oxidation-state end of the spectrum. While the electron density distribution in the cation and anion $[2 \mathbf{a}]^{+}$and $[2 \mathbf{a}]^{-}$is remarkably similar (differing only in the occupations of the totally symmetric combination of ligand-based $\pi^{*}$ orbitals) and is close to the $\left[\mathrm{Mo}^{\mathrm{V}}\left\{\mathrm{L}_{3}\right\}^{(5-n)-}\right]$ limit, the intervening neutral species has much more extensive ligand-radical character.

Finally, we note that the ability to undergo facile multiple electron-transfer reactions within a relatively narrow electrochemical window is a fundamental requirement for molecular information storage applications. We are currently exploring how these redox-responsive molecules respond when immobilized on a surface, with the ultimate goal being to find possible applications as memory devices. ${ }^{26}$

\section{EXPERIMENTAL SECTION}

Materials. The metal carbonyls $\mathrm{M}(\mathrm{CO})_{6}(\mathrm{M}=\mathrm{Cr}, \mathrm{Mo})$ were Aldrich reagents, and $n$-octane was obtained from Spectrochem, India. The ligands $\mathrm{L}^{\mathrm{a} / \mathrm{b}}$ were prepared by following the reported procedure. ${ }^{27}$ Tetrabutylammonium perchlorate was prepared and recrystallized as reported earlier. ${ }^{10 \mathrm{~b}}$ Caution! Perchlorates have to be handled with care and appropriate safety precautions! All other chemicals and solvents were of reagent grade and were used as received.

Physical Measurements. ${ }^{1} \mathrm{H}$ NMR spectra were taken on a Bruker Advance DPX 300 spectrometer, and $\mathrm{SiMe}_{4}$ was used as the internal standard. IR spectra were obtained using a Perkin-Elmer 783 spectrophotometer. A Perkin-Elmer 240C elemental analyzer was used to collect microanalytical data $(\mathrm{C}, \mathrm{H}$, and N). ESI-MS spectra were recorded on a micro mass Q-TOF mass spectrometer (serial no. YA 263). UV-NIR absorption spectra were recorded on a Perkin-Elmer Lambda 950 UV-vis spectrophotometer and a J\&M TIDAS instrument. Cyclic voltammetry was carried out in a $0.1 \mathrm{MBu}_{4} \mathrm{NClO}_{4}$ solution 
using a three-electrode configuration (platinum working electrode, platinum counter electrode, a SCE reference electrode) and a PC-controlled PAR model 273A electrochemistry system. $E_{1 / 2}$ for the ferroceniumferrocene couple under our experimental conditions was $0.39 \mathrm{~V}$. Variabletemperature $(2-290 \mathrm{~K})$ magnetization data were recorded in a $1 \mathrm{~T}$ magnetic field on a SQUID magnetometer (MPMS Quantum Design). The experimental magnetic susceptibility data were corrected for underlying diamagnetism using Pascal's tabulated constants. Simulation and analysis of the magnetic susceptibility data were made using the program julX written by E. Bill calculating through full-matrix diagonalization of the spin Hamiltonian. ${ }^{28}$ EPR spectra in the $\mathrm{X}$ band were recorded with a JEOL JES-FA200 spectrometer, and EPR simulations were done using the software provided with it. Electrical conductivities were measured by using a Systronics 304 direct reading conductivity meter.

Syntheses. Preparation of $\left[\mathrm{Cr}\left(\mathrm{L}^{a^{\bullet}-}\right)_{3}\right]$ (1a). A mixture of $218 \mathrm{mg}$ $(1.00 \mathrm{mmol})$ of $\mathrm{Cr}(\mathrm{CO})_{6}$ and $652 \mathrm{mg}(3.00 \mathrm{mmol})$ of $\mathrm{L}^{\mathrm{a}}$ was refluxed in $30 \mathrm{~mL}$ of $n$-octane for $7 \mathrm{~h}$. The solution was cooled, and the solid was collected by filtration. The crude complex was crystallized by the slow diffusion of a dichloromethane solution of the compound into hexane. Yield: $96 \%$.

$\operatorname{IR}\left(\mathrm{KBr}, \mathrm{cm}^{-1}\right): 1597[v(\mathrm{C}=\mathrm{N})+v(\mathrm{C}=\mathrm{C})], 1180[v(\mathrm{~N}=\mathrm{N})]$. ESIMS: $m / z 705[\mathrm{M}]^{+}$. Anal. Calcd for $\mathrm{C}_{33} \mathrm{H}_{24} \mathrm{~N}_{9} \mathrm{Cl}_{3} \mathrm{Cr}$ : C, 56.20; H, 3.43; $\mathrm{N}, 17.88$. Found: C, 56.21; H, 3.46; N, 17.86. ${ }^{1} \mathrm{H}$ NMR $(300 \mathrm{MHz}$, $\left.\mathrm{CDCl}_{3}, 300 \mathrm{~K}\right): \delta 7.6(\mathrm{~d}, J=6.6 \mathrm{~Hz}, 1 \mathrm{H}), 7.4(\mathrm{t}, J=7.7 \mathrm{~Hz}, 1 \mathrm{H}), 7.31$ (broad peak for $1 \mathrm{H}), 7.11$ (broad peak for $1 \mathrm{H}), 6.99(\mathrm{t}, J=7.5 \mathrm{~Hz}, 1 \mathrm{H})$, $6.84(\mathrm{t}, J=7.1 \mathrm{~Hz}, 1 \mathrm{H}), 6.26$ (broad peak for $1 \mathrm{H}), 5.29(\mathrm{~d}, J=6.6 \mathrm{~Hz}, 1 \mathrm{H})$.

Preparation of $\left[\mathrm{Cr}\left(\mathrm{L}^{b_{\bullet}-}\right)_{3}\right](\mathbf{1} \boldsymbol{b})$. Compound $\mathbf{1} \mathbf{b}$ was synthesized and crystallized following procedures similar to those for 1a. The yield and characterization data are as follows. Yield: $91 \%$. IR $\left(\mathrm{KBr}, \mathrm{cm}^{-1}\right): 1605$ $[v(\mathrm{C}=\mathrm{N})+v(\mathrm{C}=\mathrm{C})], 1176[v(\mathrm{~N}=\mathrm{N})]$. ESI-MS: $m / z 705[\mathrm{M}]^{+}$. Anal. Calcd for $\mathrm{C}_{33} \mathrm{H}_{24} \mathrm{~N}_{9} \mathrm{Cl}_{3} \mathrm{Cr}$ : C, 56.20; H, 3.43; N, 17.88. Found: C, 56.18; $\mathrm{H}, 3.45$; N, 17.86. ${ }^{1} \mathrm{H} \mathrm{NMR}\left(300 \mathrm{MHz}, \mathrm{CDCl}_{3}, 300 \mathrm{~K}\right): \delta 8.67(\mathrm{~d}, J=6.1$ $\mathrm{Hz}, 1 \mathrm{H}), 8.08(\mathrm{~d}, J=8.7 \mathrm{~Hz}, 2 \mathrm{H}), 7.90(\mathrm{t}, J=7.4 \mathrm{~Hz}, 1 \mathrm{H}), 7.81(\mathrm{~d}, J=7.1$ $\mathrm{Hz}, 1 \mathrm{H}$ ), 7.39 (broad peak for $1 \mathrm{H}), 7.03(\mathrm{~d}, J=8.5 \mathrm{~Hz}, 2 \mathrm{H}$ ).

Preparation of $[\mathbf{1 a}]]_{3}$. To a solution of $50 \mathrm{mg}(0.07 \mathrm{mmol})$ of $\mathbf{1 a}$ in $10 \mathrm{~mL}$ of dichloromethane was added dropwise a slight excess solution of $40 \mathrm{mg}(0.15 \mathrm{mmol})$ of iodine in the same solvent. The solution turned reddish-brown, and the solvent was evaporated in a rotary evaporator. The crude product thus obtained was thoroughly washed with hexane to remove excess iodine and was purified through crystallization by the slow diffusion of a dichloromethane solution into hexane. Yield: $94 \%$. IR $\left(\mathrm{KBr}, \mathrm{cm}^{-1}\right): 1654,1614[v(\mathrm{C}=\mathrm{N})+v(\mathrm{C}=\mathrm{C})], 1215,1180$ $[v(\mathrm{~N}=\mathrm{N})]$. ESI-MS: $m / z 705[\mathrm{M}]^{+}$. Molar equivalent conductance, $\Lambda\left(\mathrm{CH}_{3} \mathrm{CN}, \Omega^{-1} \mathrm{~cm}^{2} \mathrm{M}^{-1}\right):$ 141. Anal. Calcd for $\mathrm{C}_{33} \mathrm{H}_{24} \mathrm{~N}_{9} \mathrm{Cl}_{3} \mathrm{CrI}_{3}$ : C, 36.51; H, 2.23; N, 11.61. Found: C, 36.52; H, 2.24; N, 11.59.

Preparation of $[\mathbf{1 b}] l_{3}$. Compound $[\mathbf{1 b}] \mathrm{I}_{3}$ was synthesized and crystallized following procedures similar to those for $[1 \mathrm{a}] \mathrm{I}_{3}$. The yield and characterization data are as follows. Yield: $85 \%$. IR $\left(\mathrm{KBr}, \mathrm{cm}^{-1}\right)$ : $1625[v(\mathrm{C}=\mathrm{N})+v(\mathrm{C}=\mathrm{C})], 1220,1180[v(\mathrm{~N}=\mathrm{Nz})]$. ESI-MS: $m / z$ $705[\mathrm{M}]^{+}$. Molar equivalent conductance, $\Lambda\left(\mathrm{CH}_{3} \mathrm{CN}, \Omega^{-1} \mathrm{~cm}^{2} \mathrm{M}^{-1}\right)$ : 143. Anal. Calcd for $\mathrm{C}_{33} \mathrm{H}_{24} \mathrm{~N}_{9} \mathrm{Cl}_{3} \mathrm{CrI}_{3}$ : C, 36.51; H, 2.23; N, 11.61. Found: C, 36.49; H, 2.26; N, 11.59.

Preparation of $\left[\mathrm{Mo}\left(\mathrm{L}^{a^{\bullet-}-}\right)_{3}\right](\mathbf{2 a})$. A mixture of $264 \mathrm{mg}(1.00 \mathrm{mmol})$ of $\mathrm{Mo}(\mathrm{CO})_{6}$ and $652 \mathrm{mg}(3.00 \mathrm{mmol})$ of $\mathrm{L}^{\mathrm{a}}$ was refluxed in $30 \mathrm{~mL}$ of $n$ octane for $12 \mathrm{~h}$. The solution was cooled, and the solid was collected by filtration. The crude complex was crystallized by the slow diffusion of a dichloromethane solution of the compound into hexane. Yield: $89 \%$. IR $\left(\mathrm{KBr}, \mathrm{cm}^{-1}\right): 1600[v(\mathrm{C}=\mathrm{N})+v(\mathrm{C}=\mathrm{C})], 1140,1165[v(\mathrm{~N}=\mathrm{N})]$. ESI-MS: $m / z 750[\mathrm{M}]^{+}$. Anal. Calcd for $\mathrm{C}_{33} \mathrm{H}_{24} \mathrm{~N}_{9} \mathrm{Cl}_{3} \mathrm{Mo}$ : C, 52.92; $\mathrm{H}$, 3.23; N, 16.80. Found: C, 52.90; H, 3.26; N, 16.78. ${ }^{1} \mathrm{H}$ NMR $(300 \mathrm{MHz}$, $\left.\mathrm{CDCl}_{3}, 300 \mathrm{~K}\right): \delta 7.53(\mathrm{~d}, J=5.9 \mathrm{~Hz}, 1 \mathrm{H}), 7.40(\mathrm{~m}, 2 \mathrm{H}), 7.10(\mathrm{~d}, J=7.3$ $\mathrm{Hz}, 1 \mathrm{H}), 7.02(\mathrm{t}, J=7.9 \mathrm{~Hz}, 1 \mathrm{H}), 6.85(\mathrm{t}, J=7.4 \mathrm{~Hz}, 1 \mathrm{H}), 6.50(\mathrm{td}, J=1.8$ and $6.1 \mathrm{~Hz}, 1 \mathrm{H}), 5.25(\mathrm{~d}, J=7.5 \mathrm{~Hz}, 1 \mathrm{H})$.

Preparation of $\left[\mathrm{Mo}\left(\mathrm{L}^{b \bullet-}\right)_{3}\right](\mathbf{2} \boldsymbol{b})$. Compound $\mathbf{2} \mathbf{b}$ was synthesized and crystallized following procedures similar to those for $\mathbf{2 a}$. The yield and characterization data are as follows. Yield: $87 \%$. IR $\left(\mathrm{KBr}, \mathrm{cm}^{-1}\right): 1610$ $[v(\mathrm{C}=\mathrm{N})+v(\mathrm{C}=\mathrm{C})], 1140,1160[v(\mathrm{~N}=\mathrm{N})]$. ESI-MS: $m / z 750$ $[\mathrm{M}]^{+}$. Anal. Calcd for $\mathrm{C}_{33} \mathrm{H}_{24} \mathrm{~N}_{9} \mathrm{Cl}_{3} \mathrm{Mo}$ : C, 52.92; H, 3.23; N, 16.8 . Found: C, 52.94; H, 3.26; N, 16.77. ${ }^{1} \mathrm{H} \mathrm{NMR}\left(300 \mathrm{MHz}, \mathrm{CDCl}_{3}, 300 \mathrm{~K}\right)$ : $\delta 8.71(\mathrm{~d}, J=5.8 \mathrm{~Hz}, 1 \mathrm{H}), 8.06(\mathrm{~d}, J=9.0 \mathrm{~Hz}, 2 \mathrm{H}), 7.89(\mathrm{t}, J=8.1 \mathrm{~Hz}$, $1 \mathrm{H}), 7.80(\mathrm{~d}, J=7.3 \mathrm{~Hz}, 1 \mathrm{H}), 7.4(\mathrm{t}, J=6.0 \mathrm{~Hz}, 1 \mathrm{H}), 7.03(\mathrm{~d}, J=8.8 \mathrm{~Hz}, 2 \mathrm{H})$.

Preparation of $[\mathbf{2 a}]_{l_{3}}$. To a solution of $55 \mathrm{mg}(0.073 \mathrm{mmol})$ of $\mathbf{2 a}$ in $15 \mathrm{~mL}$ of dichloromethane was added dropwise a slight excess solution of $45 \mathrm{mg}(0.17 \mathrm{mmol})$ of iodine in the same solvent. The solution turned reddish-brown, and the solvent was evaporated in a rotary evaporator. The crude product thus obtained was thoroughly washed with hexane to remove excess iodine and was purified through crystallization by the slow diffusion of a dichloromethane solution into hexane. Yield: $89 \%$. IR $\left(\mathrm{KBr}, \mathrm{cm}^{-1}\right): 1596[v(\mathrm{C}=\mathrm{N})+v(\mathrm{C}=\mathrm{C})], 1140,1195[v(\mathrm{~N}=\mathrm{N})]$. ESI-MS: $m / z 750[\mathrm{M}]^{+}$. Molar equivalent conductance, $\Lambda\left(\mathrm{CH}_{3} \mathrm{CN}\right.$, $\left.\Omega^{-1} \mathrm{~cm}^{2} \mathrm{M}^{-1}\right)$ : 139. Anal. Calcd for $\mathrm{C}_{33} \mathrm{H}_{24} \mathrm{~N}_{9} \mathrm{Cl}_{3} \mathrm{MoI}_{3}: \mathrm{C}, 35.09 ; \mathrm{H}$, 2.14; N, 11.16. Found: C, 35.11; H, 2.17; N, 11.18.

Preparation of $[\mathbf{2} \boldsymbol{b}]]_{3}$. Compound $[\mathbf{2 b}] \mathrm{I}_{3}$ was synthesized and crystallized following procedures similar to those for $[2 \mathrm{a}] \mathrm{I}_{3}$. The yield and characterization data are as follows. Yield: $85 \%$. IR $\left(\mathrm{KBr}, \mathrm{cm}^{-1}\right)$ : $1598[v(\mathrm{C}=\mathrm{N})+v(\mathrm{C}=\mathrm{C})], 1135,1195[v(\mathrm{~N}=\mathrm{N})]$. ESI-MS: $m / z: 750$ $[\mathrm{M}]^{+}$. Molar equivalent conductance, $\Lambda\left(\mathrm{CH}_{3} \mathrm{CN}, \Omega^{-1} \mathrm{~cm}^{2} \mathrm{M}^{-1}\right): 138$. Anal. Calcd for $\mathrm{C}_{33} \mathrm{H}_{24} \mathrm{~N}_{9} \mathrm{Cl}_{3} \mathrm{MoI}_{3}$ : C, 35.09; $\mathrm{H}, 2.14 ; \mathrm{N}, 11.16$. Found: C, 35.08; H, 2.16; N, 11.17.

Crystallography. Crystallographic data for compounds $[\mathbf{1 a}] \cdot \mathrm{CH}_{2} \mathrm{Cl}_{2}$, $[\mathbf{1 a}] \mathrm{I}_{3},[\mathbf{2 a}] \cdot 2 \mathrm{CH}_{2} \mathrm{Cl}_{2}$, and $[\mathbf{2 a}] \mathrm{I}_{3}$ are collected in Table 5. Suitable $\mathrm{X}$-ray-quality crystals of these compounds are obtained by the slow evaporation of a dichloromethane-hexane solution of the compound. All data were collected on a Bruker SMART APEX-II diffractometer, equipped with graphite-monochromated Mo $\mathrm{K} \alpha$ radiation $(\lambda=$ $0.71073 \AA$ ) and were corrected for Lorentz polarization effects. [1a] $\cdot \mathrm{CH}_{2} \mathrm{Cl}_{2}$ : A total of 16029 reflections were collected, of which 5954 were unique $\left(R_{\text {int }}=0.031\right)$, satisfying the $I>2 \sigma(I)$ criterion, and were used in subsequent analysis. [1 $1 \mathrm{a}] \mathrm{I}_{3}$ : A total of 34388 reflections were collected, of which 6967 were unique $\left(R_{\text {int }}=0.058\right)$. [2a] $2 \mathrm{CH}_{2} \mathrm{CL}_{2}$ : A total of 44121 reflections were collected, of which 6600 were unique $\left(R_{\text {int }}=0.032\right)$. [2a] $\mathrm{I}_{3}$ : A total of 34967 reflections were collected, of which 6567 were unique $\left(R_{\text {int }}=0.050\right)$. The structures were solved by employing the SHELXS-97 program package ${ }^{29}$ and were refined by full-matrix least squares based on $F^{2}$ (SHELXL-97). ${ }^{30}$ All hydrogen atoms were added in calculated positions.

\section{— COMPUTATIONAL METHODS}

All DFT calculations presented in this paper were carried out using the Gaussian 03 program package. ${ }^{31}$ Geometry optimizations were performed without imposing geometric constraints ( $C_{1}$ symmetry), and obtained stationary points were subsequently confirmed to be minima by vibrational analysis (no imaginary frequencies). All calculations utilized the B3LYP hybrid functional. ${ }^{32}$ The TZVP basis set ${ }^{33}$ of triple- $\zeta$ quality with one set of polarization functions was used on chromium and nitrogen atoms (all except one nitrogen atom in each of the three azo units are directly coordinating to the metal center). The def2-TZVP basis set ${ }^{34}$ as obtained from the EMSL Basis Set Library ${ }^{35}$ was used for molybdenum. This basis set is of triple- $\zeta$ quality with an effective core potential (ecp28) for core functions. ${ }^{36}$ For the carbon, chlorine, and hydrogen atoms, slightly smaller polarized split-valence SVP basis sets ${ }^{37}$ were used, which are of double- $\zeta$ quality in the valence region and contain a polarizing set of $\mathrm{d}$ functions on the non-hydrogen atoms. The broken-symmetry approach first proposed by Ginsberg ${ }^{38}$ and Noodleman et al. ${ }^{39}$ has been employed for all chromium and molybdenum complexes. A range of spin-polarized initial densities was tried in each case $[\mathrm{BS}(3,3), \mathrm{BS}(2,2)$, etc.], but in all cases, different guesses (with the same total multiplicity) converged to the same minimum. Exchange coupling constants $J$ were 
calculated from the energy differences between the high-spin and corresponding broken-symmetry state according to the approach of Yamaguchi et al. ${ }^{40}$

$$
\begin{aligned}
& H_{\mathrm{HDvV}}=-2 J \hat{S}_{1} \cdot \hat{S}_{2} \\
& J=-\frac{E_{\mathrm{HS}}-E_{\mathrm{BS}}}{\left\langle S^{2}\right\rangle_{\mathrm{HS}}-\left\langle S^{2}\right\rangle_{\mathrm{BS}}}
\end{aligned}
$$

where $\left\langle S^{2}\right\rangle$ is the expectation value of the square of the total spin angular momentum operator. Percentage compositions of canonical and corresponding molecular orbitals were calculated using the AOMix program. $^{41}$ Mulliken spin densities were used for analysis of the spin populations on ligand and metal centers. ${ }^{42}$

\section{ASSOCIATED CONTENT}

S Supporting Information. Experimental and DFT characterization details and X-ray crystallographic files in CIF format for $1 \mathrm{a},[1 \mathrm{1}] \mathrm{I}_{3}, \mathbf{2 a}$, and $[2 \mathrm{a}] \mathrm{I}_{3}$. This material is available free of charge via the Internet at http://pubs.acs.org.

\section{AUTHOR INFORMATION}

\section{Corresponding Author}

*E-mail: john.mcgrady@chem.ox.ac.uk (J.E.M.), icsg@iacs.res.in (S.G.). Tel: +91-33-24734971. Fax: +91-33-24732805.

\section{Present Addresses}

${ }^{\S}$ Chemistry and Biomimetics Group, CSIR-Central Mechanical Engineering Research Institute, Mahatma Gandhi Avenue, Durgapur 713209, India.

\section{ACKNOWLEDGMENT}

The research was supported by Department of Science and Technology (DST) and Council for Scientific and Industrial Research (CSIR), India, funded projects, SR/S1/IC/0031/2010 and 01/2358/09/EMR-II respectively. We are thankful to Professor S. Bhattacharya and Dr. Tapan K. Paine for helpful discussions. Crystallography was performed at the DST-funded National Single Crystal Diffractometer facility at the Department of Inorganic Chemistry, Indian Association for the Cultivation of Science. S.J. and N.D.P. thank the CSIR, New Delhi, India, for fellowship support. T.K. acknowledges financial support from the University of Oxford.

\section{REFERENCES}

(1) (a) Redox Signaling and Regulation in Biology and Medicine; Jacob, C., Winyard, P. G., Eds.; Wiley-VCH: New York, 2009. (b) Lillig, C. H.; Holmgren, A. Antioxid. Redox Signaling 2007, 9, 25. (c) Peng, D.-W.; Abruña, H. D. Anal. Chem. 1998, 70, 3162. (d) Sono, M.; Roach, M. P.; Coulter, E. D.; Dawson, J. H. Chem. Rev. 1996, 96, 2841. (e) Stubbe, J.; van der Donk, W. A. Chem. Rev. 1998, 98, 705.

(2) (a) Chirik, P. J.; Wieghardt, K. Science 2010, 327, 794. (b) Tondreau, A. M.; Milsmann, C.; Patrick, A. D.; Hoyt, H. M.; Lobkovsky, E.; Wieghardt, K.; Chirik, P. J. J. Am. Chem. Soc. 2010, 132, 15046. (c) van der Vlugt, J. I.; Reek, J. N. H. Angew. Chem., Int. Ed. 2009, 48, 8832.

(3) (a) Hess, C. R.; Weyhermüller, T.; Bill, E.; Wieghardt, K. Inorg. Chem. 2010, 49, 5686. (b) Godula, K.; Sames, D. Science 2006, 312, 67. (c) Bai, G.; Stephan, D. W. Angew. Chem., Int. Ed. 2007, 46, 1856. (d) Arikawa, Y.; Asayama, T.; Itatani, K.; Onishi, M. J. Am. Chem. Soc. 2008, 130, 10508.

(4) (a) Bhattacharya, S.; Boone, S. R.; Fox, G. A.; Pierpont, C. G. J. Am. Chem. Soc. 1990, 112, 1088. (b) Bhattacharya, S.; Pierpont, C. G.
Inorg. Chem. 1991, 30, 1511. (c) Haga, M.; Dodsworth, E. S.; Lever, A. B. P.; Boone, S. R.; Pierpont, C. G. J. Am. Chem. Soc. 1986, 108, 7413. (d) Boone, S. R.; Pierpont, C. G. Inorg. Chem. 1987, 26, 1769. (e) Bhattacharya, S.; Pierpont, C. G. Inorg. Chem. 1994, 33, 6038. (f) Haga, M.; Isobe, K.; Boone, S. R.; Pierpont, C. G. Inorg. Chem. 1990, 29, 3795.

(5) (a) Kapre, R. R.; Bothe, E.; Weyhermüller, T.; DeBeer George, S.; Wieghardt, K. Inorg. Chem. 2007, 46, 5642. (b) Tenderholt, A. L.; Szilagyi, R. K.; Holm, R. H.; Hodgeson, K. O.; Hedman, B.; Solomon, E. I. Inorg. Chem. 2008, 47, 6382. (c) Sproules, S.; Wieghardt, K. Coord. Chem. Rev. 2011, 255, 837.

(6) (a) Ghosh, A. K.; Peng, S. M.; Paul, R. L.; Ward, M. D.; Goswami, S. J. Chem. Soc., Dalton Trans. 2001, 336. (b) Mitra, K. N.; Majumdar, P.; Peng, S. M.; Castiñeiras, A.; Goswami, S. Chem. Commun. 1997, 1267. (c) Mitra, K. N.; Choudhury, S.; Castiñeiras, A.; Goswami, S. J. Chem. Soc., Dalton Trans. 1998, 2901.

(7) (a) Banerjee, P.; Sproules, S.; Weyhermüller, T.; DeBeer George, S.; Wieghardt, K. Inorg. Chem. 2009, 48, 5829. (b) Kapre, R. R.; Bothe, E.; Weyhermüller, T.; DeBeer George, S.; Muresan, N.; Wieghardt, K. Inorg. Chem. 2007, 46, 7827. (c) Sproules, S.; Benedito, F. L.; Bill, E.; Weyhermüller, T.; DeBeer George, S.; Wieghardt, K. Inorg. Chem. 2009, 48, 10926. (d) Benedito, F. L.; Petrenko, T.; Bill, E.; Weyhermüller, T.; Wieghardt, K. Inorg. Chem. 2009, 48, 10913. (e) Sproules, S.; Weyhermüller, T.; DeBeer George, S.; Wieghardt, K. Inorg. Chem. 2010, 49, 5241. (f) Roy, N.; Sproules, S.; Bill, E.; Weyhermüller, T.; Wieghardt, K. Inorg. Chem. 2008, 47, 10911. (g) Muresan, N.; Chlopek, K.; Weyhermüller, T.; Neese, F.; Wieghardt, K Inorg. Chem. 2007, 46, 5327. (h) Chun, H.; Bill, E.; Weyhermüller, T.; Wieghardt, K. Inorg. Chem. 2003, 42, 5612. (i) Kapre, R. R.; Ray, K.; Sylvestre, I.; Weyhermüller, T.; DeBeer George, S.; Neese, F.; Wieghardt, K. Inorg. Chem. 2006, 45, 3499. (j) Ray, K.; Begum, A.; Weyhermüller, T.; Piligkos, S.; van Slageren, J.; Neese, F.; Wieghardt, K. J. Am. Chem. Soc. 2005, 127, 4403.

(8) (a) Paul, N.; Samanta, S.; Goswami, S. Inorg. Chem. 2010, 49, 2649. (b) Sanyal, A.; Chatterjee, S.; Castiñeiras, A.; Sarkar, B.; Singh, P.; Fiedler, J.; Zálǐ̌, S.; Kaim, W.; Goswami, S. Inorg. Chem. 2007, 46, 8584. (c) Sanyal, A.; Banerjee, P.; Lee, G.-H.; Peng, S.-M.; Hung, C.-H.; Goswami, S. Inorg. Chem. 2004, 43, 7456. (d) Samanta, S.; Singh, P.; Fiedler, J.; Zálišs, S.; Kaim, W.; Goswami, S. Inorg. Chem. 2008, 47, 1625.

(9) (a) Sarkar, B.; Patra, S.; Fiedler, J.; Sunoj, R. B.; Janardanan, D.; Lahiri, G. K.; Kaim, W. J. Am. Chem. Soc. 2008, 130, 3532. (b) Blanchard, S.; Neese, F.; Bothe, E.; Bill, E.; Weyhermüller, T.; Wieghardt, K. Inorg. Chem. 2005, 44, 3636. (c) Ye, S.; Sarkar, B.; Lissner, F.; Schleid, T.; van Slageren, J.; Fiedler, J.; Kaim, W. Angew. Chem., Int. Ed. 2005, 44, 2103.

(10) (a) Sadler, J. L.; Bard, A. J. J. Am. Chem. Soc. 1968, 90, 1979. (b) Goswami, S.; Mukherjee, R. N.; Chakravorty, A. Inorg. Chem. 1983, 22, 2825.

(11) (a) Shivakumar, M.; Pramanik, K.; Ghosh, P.; Chakravorty, A. J. Chem. Soc., Chem. Commun. 1998, 2103. (b) Shivakumar, M.; Pramanik, K.; Ghosh, P.; Chakravorty, A. Inorg. Chem. 1998, 37, 5968. (c) Doslik, N.; Sixt, T.; Kaim, W. Angew. Chem., Int. Ed. 1998, 37, 2403.

(12) Sinan, M.; Panda, M.; Banerjee, P.; Shinisha, C. B.; Sunoj, R. B.; Goswami, S. Org. Lett. 2009, 11, 3218 and references cited therein.

(13) Paul, N. D.; Krämer, T.; McGrady, J. E.; Goswami, S. Chem. Commun. 2010, 46, 7124.

(14) (a) Marabella, C. P.; Enemark, J. H.; Newton, W. E.; McDoland, J. W. Inorg. Chem. 1982, 21, 623. (b) Ittel, S. D.; Ibers, J. A. Inorg. Chem. 1973, 12, 2290.

(15) Ackermann, M. N.; Barton, C. R.; Deodene, C. J.; Specht, E. M.; Keill, S. C.; Schreiber, W. E.; Kim, H. Inorg. Chem. 1989, 28, 397.

(16) Ackermann, M. N.; Kiihne, S. R.; Saunders, P. A.; Barnes, C. E.; Stallings, S. C.; Kim, H.; Woods, C.; Lagunoff, M. Inorg. Chim. Acta 2002, 334, 193.

(17) Saha, A.; Das, C.; Goswami, S.; Peng, S.-M. Indian J. Chem., Sect. A 2001, 40A, 198.

(18) (a) Chun, H.; Verani, C. N.; Chaudhuri, P.; Bothe, E.; Bill, E.; Weyhermüller, T.; Wieghardt, K. Inorg. Chem. 2001, 40, 4157. (b) Herzog, S.; Aul, H. Z. Naturforsch. 1960, 15B, 617. (c) Wulf, V. E.; Herzog, S. Z. Anorg. Allg. Chem. 1972, 387, 81. 
(19) (a) Buchanan, R. M.; Downs, H. H.; Shorthill, W. B.; Pierpont, C. G.; Kessel, S. L.; Hendrickson, D. N. J. Am. Chem. Soc. 1978, 100, 4318. (b) Buchanan, R. M.; Kessel, S. L.; Downs, H. H.; Pierpont, C. G.; Hendrickson, D. N. J. Am. Chem. Soc. 1978, 100, 7894. (c) Downs, H. H.; Buchanan, R. M.; Pierpont, C. G. Inorg. Chem. 1979, 18, 1736.

(20) Kahn, O. Molecular Magnetism; VCH Publishers: New York, 1993.

(21) Soda, T.; Kitagawa, Y.; Onishi, T.; Takano, Y.; Shigeta, Y.; Nagao, H.; Yoshioka, Y.; Yamaguchi, K. Chem. Phys. Lett. 2000, 319, 223.

(22) Chun, H.; Chaudhuri, P.; Weyhermüller, T.; Wieghardt, K. Inorg. Chem. 2002, 41, 790.

(23) Psillakis, E.; Shonfield, P. K. A.; Jouaiti, A.-A.; Maher, J. P.; McCleverty, J. A.; Ward, M. D. J. Chem. Soc., Dalton Trans. 2000, 241.

(24) (a) Herebian, D.; Wieghardt, K.; Neese, F. J. Am. Chem. Soc. 2003, 125, 9116. (b) Herebian, D.; Wieghardt, K. E.; Neese, F. J. Am. Chem. Soc. 2003, 125, 10997. (c) Khusniyarov, M. M.; Weyhermüller, T.; Bill, E.; Wieghardt, K. J. Am. Chem. Soc. 2009, 131, 1208. (d) Neese, F. J. Biol. Inorg. Chem. 2006, 11, 702.

(25) Khusniyarov, M. M.; Bill, E.; Weyhermüller, T.; Bothe, E.; Wieghardt, K. Angew. Chem., Int. Ed. 2011, 50, 1652.

(26) Padmaja, K.; Youngblood, W. J.; Wei, L.; Bocian, D. F.; Lindsey, J. S. Inorg. Chem. 2006, 45, 5479 and references cited therein.

(27) Campbell, N.; Henderson, A. W.; Taylor, D. J. Chem. Soc. 1953, 1281.

(28) Available through http://ewww/mpi-heim.mpg.de/bac/logins/ bill/julX en.php.

(29) Sheldrick, G. M. Acta Crystallogr., Sect. A 1990, 46, 467.

(30) Sheldrick, G. M. SHELXL 97, Program for the refinement of crystal structures; University of Göttingen: Göttingen, Germany, 1997.

(31) Frisch, M. J.; Trucks, G. W.; Schlegel, H. B.; Scuseria, G. E.; Robb, M. A.; Cheeseman, J. R.; Montgomery, J. A., Jr.; Vreven, T.; Kudin, K. N.; Burant, J. C.; Millam, J. M.; Iyengar, S. S.; Tomasi, J.; Barone, V.; Mennucci, B.; Cossi, M.; Scalmani, G.; Rega, N.; Petersson, G. A.; Nakatsuji, H.; Hada, M.; Ehara, M.; Toyota, K.; Fukuda, R.; Hasegawa, J.; Ishida, M.; Nakajima, T.; Honda, Y.; Kitao, O.; Nakai, H.; Klene, M.; Li, X.; Knox, J. E.; Hratchian, H. P.; Cross, J. B.; Bakken, V.; Adamo, C.; Jaramillo, J.; Gomperts, R.; Stratmann, R. E.; Yazyev, O.; Austin, A. J.; Cammi, R.; Pomelli, C.; Ochterski, J. W.; Ayala, P. Y.; Morokuma, K.; Voth, G. A.; Salvador, P.; Dannenberg, J. J.; Zakrzewski, V. G.; Dapprich, S.; Daniels, A. D.; Strain, M. C.; Farkas, O.; Malick, D. K.; Rabuck, A. D.; Raghavachari, K.; Foresman, J. B.; Ortiz, J. V.; Cui, Q.; Baboul, A. G.; Clifford, S.; Cioslowski, J.; Stefanov, B. B.; Liu, G.; Liashenko, A.; Piskorz, P.; Komaromi, I.; Martin, R. L.; Fox, D. J.; Keith, T.; Al-Laham, M. A.; Peng, C. Y.; Nanayakkara, A.; Challacombe, M.; Gill, P. M. W.; Johnson, B.; Chen, W.; Wong, M. W.; Gonzalez, C.; Pople, J. A. Gaussian 03, revision E.01; Gaussian, Inc.: Wallingford, CT, 2004.

(32) (a) Becke, A. D. J. Chem. Phys. 1993, 98, 5648. (b) Lee, C.; Yang, W.; Parr, R. G. Phys. Rev. B: Condens. Matter Mater. Phys. 1988, 37, 785. (c) Vosko, S. H.; Wilk, L.; Nusair, M. Can. J. Phys. 1980, 58, 1200. (d) Stephens, P. J.; Devlin, F. J.; Chabalowski, C. F.; Frisch, M. J. J. Phys. Chem. 1994, 98, 11623.

(33) Schäfer, A.; Huber, C.; Ahlrichs, R. J. Chem. Phys. 1994, 100, 5829.

(34) Weigend, F.; Ahlrichs, R. Phys. Chem. Chem. Phys. 2005, 7, 3297.

(35) (a) Schuchardt, K. L.; Didier, B. T.; Elsethagen, T.; Sun, L.; Gurumoorthi, V.; Chase, J.; Li, J.; Windus, T. L. J. Chem. Inf. Model. 2007, 47, 1045. (b) Feller, D. J. Comput. Chem. 1996, 17, 1571.

(36) Andrae, D.; Häussermann, U.; Dolg, M.; Stoll, H.; Preuss, H. Theor. Chim. Acta 1990, 77, 123.

(37) Schäfer, A.; Horn, H.; Ahlrichs, R. J. Chem. Phys. 1992, 97, 2571.

(38) Ginsberg, A. P. J. Am. Chem. Soc. 1980, 102, 111.

(39) (a) Noodleman, L.; Case, D. A.; Aizman, A. J. Am. Chem. Soc. 1988, 110, 1001. (b) Noodleman, L.; Davidson, E. R. Chem. Phys. 1986, 109, 131. (c) Noodleman, L.; Norman, J. G., Jr.; Osborne, J. H.; Aizman, C.; Case, D. A. J. Am. Chem. Soc. 1985, 107, 3418. (d) Noodleman, L. J. Chem. Phys. 1981, 74, 5737.
(40) (a) Applied Quantum Chemistry; Yamaguchi, K., Takahara, Y., Fueno, T., Smith, V. H., Eds.; Reidel: Dordrecht, The Netherlands, 1986; p 155. (b) Soda, T.; Kitagawa, Y.; Onishi, T.; Takano, Y.; Shigeta, Y.; Nagao, H.; Yoshioka, Y.; Yamaguchi, K. Chem. Phys. Lett. 2000, 319, 223.

(41) (a) Gorelsky, S. I. AOMix: Program for Molecular Orbital Analysis; University of Ottawa: Ottawa, Canada, 2010; http://www.sg-chem.net/. (b) Gorelsky, S. I.; Lever, A. B. P. J. Organomet. Chem. 2001, 635, 187.

(42) Mulliken, R. S. J. Chem. Phys. 1955, 23, 1833. 